\title{
Levelized cost of energy (LCOE) metric to characterize solar absorber coatings for the CSP industry
}

Antoine Boubault*, Clifford K. Ho, Aaron Hall, Timothy N. Lambert, Andrea Ambrosini

*anbouba@sandia.gov

Concentrating Solar Technologies Department, Sandia National Laboratories, P.O. Box 5800, Albuquerque, New Mexico, 87185-MS1127, USA

\begin{abstract}
The contribution of each component of a power generation plant to the levelized cost of energy (LCOE) can be estimated and used to increase the power output while reducing system operation and maintenance costs. The LCOE is used in order to quantify solar receiver coating influence on the LCOE of solar power towers. Two new parameters are introduced: the absolute levelized cost of coating (LCOC) and the LCOC efficiency. Depending on the properties, aging, costs, and temperature, the absolute LCOC enables quantifying the cost-effectiveness of absorber coatings, as well as finding optimal operating conditions. The absolute LCOC is investigated for different hypothetic coatings depending on their aging, costs, selectivity, and temperature. The absolute LCOC model is demonstrated on Pyromark 2500 paint. Results show that absorber coatings are favorable in most cases, even at significant costs. Optimal reapplication intervals range from one to five years. At receiver temperatures greater than $700{ }^{\circ} \mathrm{C}$, non-selective coatings are not always worthwhile while durable selective coatings consistently reduce the LCOE-up to $12 \%$ of the value obtained for an uncoated receiver. The absolute LCOC is a powerful tool to characterize and compare different coatings, not only considering their initial efficiencies but also including their durability.
\end{abstract}

\section{Keywords}

LCOE; LCOC; Aging; Durability; Solar absorber; Coating

\section{Highlights}

- Optimal coating reapplication intervals that minimize the LCOE exist

- Absolute LCOC shows higher sensitivity to the coating degradation than to its cost

- Selective coatings represent considerable LCOE reductions at high temperatures

- Current and future absolute LCOCs of Pyromark 2500 are estimated

- Receiver coatings could reduce the LCOE by up to $12 \%$ 


\section{Nomenclature}

\begin{tabular}{|c|c|c|c|}
\hline LCOE & Levelized Cost of Energy $\left(\$ \mathrm{MW}^{-1} \mathrm{~h}^{-1}\right)$ & $\alpha$ & hemispherical absorptance (-) \\
\hline LCOC & Levelized Cost of Coating $\left(\$ \mathrm{MW}^{-1} \mathrm{~h}^{-1}\right)$ & $\varepsilon$ & hemispherical emittance (-) \\
\hline $\mathrm{C}$ & annualized costs $\left(\$ \mathrm{yr}^{-1}\right)$ & $\phi$ & flux $(\mathrm{W})$ \\
\hline $\mathrm{E}$ & annualized energy ( $\mathrm{MW} \mathrm{h} \mathrm{yr}{ }^{-1}$ ) & $\sigma$ & Stefan-Boltzmann constant $\left(\mathrm{W} \mathrm{m}^{-2} \mathrm{~K}^{-4}\right)$ \\
\hline SL & service lifetime (years) & & \\
\hline $\mathrm{f}$ & function (-) & \multicolumn{2}{|c|}{ Subscripts } \\
\hline $\mathrm{x}$ & real number (-) & $\mathrm{c}$ & component \\
\hline A & degradation factor or degradation factor of & coating & coating \\
\hline \multicolumn{2}{|c|}{ the coating $(-)$} & & reference \\
\hline RI & coating reapplication interval (years) & $\mathrm{e}$ & electric \\
\hline DT & coating reapplication downtime (days) & os & on-sun \\
\hline $\mathrm{t}$ & time (hours or years) & 0 & initial \\
\hline $\mathrm{S}$ & receiver surface $\left(\mathrm{m}^{2}\right)$ & 1 & 1 \\
\hline $\mathrm{T}$ & receiver surface temperature $(\mathrm{K})$ & 2 & 2 \\
\hline h & receiver external convection coefficient & th & thermal \\
\hline \multirow{2}{*}{\multicolumn{2}{|c|}{$\left(\mathrm{W} \mathrm{m} \mathrm{m}^{-2} \mathrm{~K}^{-1}\right)$}} & nom & nominal \\
\hline & & air & air \\
\hline \multicolumn{2}{|c|}{ Greek symbols } & $\mathrm{i}$ & incident \\
\hline$\eta$ & efficiency (-) & & \\
\hline
\end{tabular}

\section{Introduction}

In the Concentrating Solar Power (CSP) industry, reflective and absorber coatings are extensively used to enhance the optical properties of key solar power plant components. On heliostats, coatings provide high reflectance, soiling protection and durability [1-4]; on solar receiver surfaces, high-temperature absorber coatings allow for enhanced absorption of the concentrated solar radiation and act as protective barriers against oxidation. In particular, increasing interest is directed towards the development of hightemperature solar selective coatings [5-15].

With the widespread deployment of CSP power plants throughout the world—notably solar power towers-, solar industries demand for more efficient and durable coatings. A common approach consists of developing new components and new materials that yield higher efficiencies. From an economical point of view, such development must be eventually associated with a cost reduction. At the industry level, not only is the efficiency important, but also durability, costs, and large-scale applicability are crucial to drive the levelized cost of energy (LCOE) of solar technologies down. As an illustration, a robust and stable component with average performance might be preferable and might lead to a lower LCOE than a higher-performance component that requires restricted operation and significant maintenance due to poor durability. 
The LCOE has become one the most referred-to criteria used for identifying the most cost-effective energy production technologies. In the same time, LCOE is the subject of controversy because it depends on many parameters some of which are partially known and/or associated with large uncertainties. The emerging CSP technologies in the market lead to a wide variety of LCOE values [16] that can be easily misinterpreted [17]. While the LCOE is an economic parameter, we propose to apply it at the scientific level by taking into account additional factors such as performance, aging and costs, in order to optimize operation and maintenance of components. Formerly, the marginal LCOC (levelized cost of coating) was introduced to evaluate possible cost reductions generated by the use of an absorber coating [18] but it did not reflect variations in the LCOE. In this paper, a similar approach is presented with the introduction of the absolute LCOC model which uses the LCOE metric to quantify the influence of the coating on the overall cost and performance of a power plant, in that case a solar power tower. In particular, the absolute LCOC of hypothetic coatings is calculated depending on their degradation, costs, reapplication interval, temperature and optical properties. The absolute LCOC is demonstrated on Pyromark 2500, one of the most common high-temperature absorber coatings in the tower industry. Experimental aging data from Solar One power plant are used to estimate current and future contributions of Pyromark on the LCOE. As a result, the absolute LCOC model can be used as a tool to help making decisions on component selection, operation, and maintenance.

\section{Definition of the absolute LCOC and the LCOC efficiency}

The LCOE metric accounts for the total cost of every component of a plant, over the total electrical energy produced. It is convenient to annualize the costs and the energy production. The LCOE is defined as the sum of the annualized costs, $C_{c}$, of each component over the annualized electrical energy produced $E_{e}$ (eq. 1):

$$
L C O E=\frac{\sum_{c} C_{c}}{E_{e}}
$$

LCOE is expressed in $\$ \mathrm{MW}^{-1} \mathrm{~h}^{-1}$. Component $c$ can be any component, sub-component or group of subcomponents. $C_{c}$ includes the initial costs as well as the operation, maintenance and possible disposal costs of this component.

Cylindrical external receivers are currently the most common design for commercial solar towers (Gemasolar, Ivanpah, Crescent Dunes, eSolar, and others). These receivers are generally made of panels, consisting of metallic tubes coated with an absorber material (Figure 1Error! Reference source not found.). 


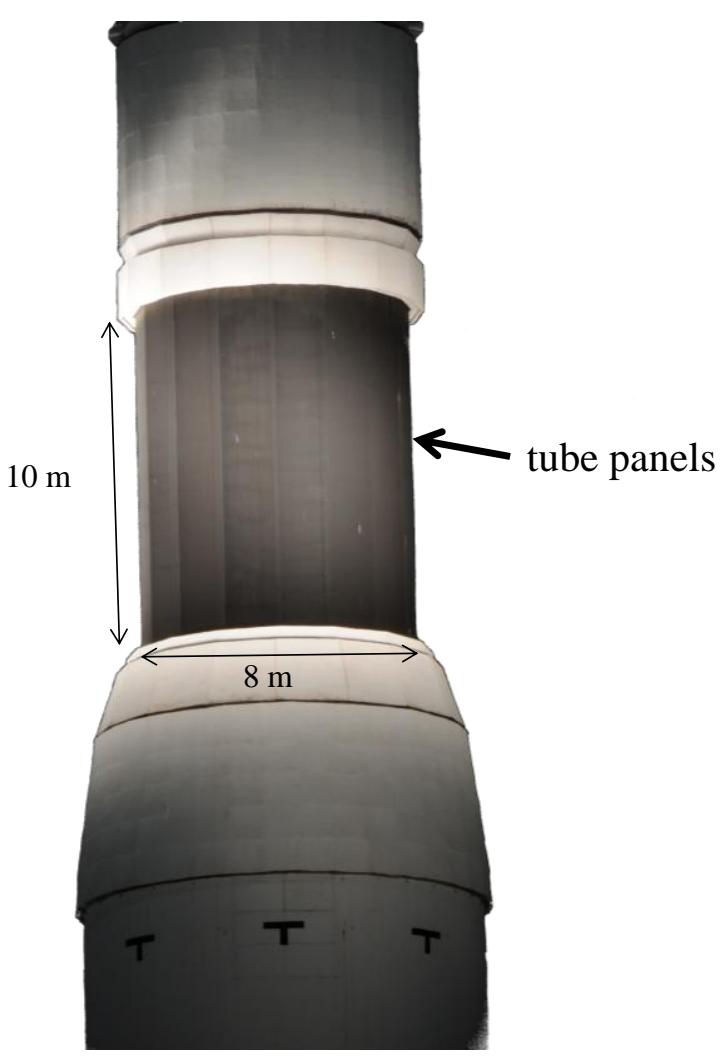

Figure 1. Gemasolar $120 \mathrm{MW}_{\mathrm{t}}$ receiver constituted of tube panels

The receiver surface has a crucial role: it is the material that converts the concentrated solar radiation into heat, and transfers it to the working fluid. The electricity output depends directly on the amount of radiation that the receiver is capable of absorbing. High solar radiation and high temperatures at the receiver surface are responsible for degradation mechanisms leading to a decreased efficiency [19-21]. When considering the cost of a receiver, the maintenance and durability must be taken into account in addition to the initial costs.

We define the absolute LCOC of a coating as the difference between the LCOE of the plant in presence of the coating and a reference LCOE value (eq. 2):

$$
L C O C=L C O E_{\text {coating }}-L C O E_{\text {ref }}
$$

The reference value is chosen as the LCOE of the same plant consisting of an uncoated receiver. The expression of the absolute LCOC is given by (eq. 3) where $C_{\text {coating }}$ is the annualized cost of the coating and $C$ the annualized cost of all other components. $E_{e, \text { coating }}$ and $E_{e, \text { ref }}$ are the annualized electrical energy that would be produced with and without the coating, respectively. $C$ does not include any benefits or revenue due to the plant. $C_{\text {coating }} / E_{e, \text { coating }}$ is the marginal LCOC previously introduced [18]. 


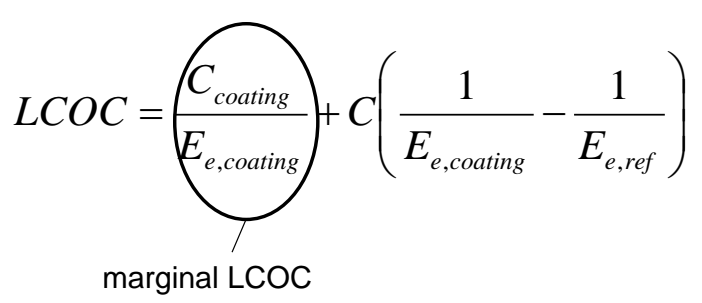

The absolute LCOC expresses a direct increase or decrease of the LCOE due to the coating cost and the additional or reduced annualized energy output. The reference LCOE is calculated by considering a noncoated receiver (bare metal). A negative absolute LCOC means a lower LCOE due to the coating, a positive value means a higher value.

Following the definition of the absolute LCOC, we introduce the "LCOC efficiency" as the ratio between the LCOC of a coating and the LCOC of an ideal coating (ideal optical properties $\left(\alpha_{S}=1, \varepsilon=0\right.$ ), no cost and no degradation) (eq. 4).

$$
\eta_{L C O C}=\frac{L C O C}{L C O C_{\text {ideal }}}
$$

$L C O C_{\text {ideal }}$ corresponds to the minimum possible value of the absolute LCOC in prescribed conditions and is always negative as it considers an ideal coating with no additional cost. Thus, $\eta_{L C O C}$ theoretically ranges from $-\infty$ to 1 . A negative LCOC efficiency value means the coating increases the LCOE (unfavorable). LCOC efficiency between 0 and 1 means the coating decreases the LCOE (favorable). A value close to 1 indicates a coating that is close to ideal (selective, low cost and durable).

\section{Model considerations and method}

We consider a hypothetical $100 \mathrm{MW}_{\mathrm{e}}$ solar tower located close to Las Vegas, NV. Table 1 presents the metrics assumed, inspired by commercial plant Crescent Dunes in Tonapah, NV, USA.

Table 1. Solar power tower main metrics

\begin{tabular}{lr}
\hline Electrical power output $\left(\mathrm{MW}_{\mathrm{e}}\right)$ & 100 \\
Plant service lifetime $S L$ (years) & 30 \\
Annual Direct Normal Irradiance $\left(\mathrm{kW} \mathrm{h} \mathrm{m}^{-2} \mathrm{y}^{-1}\right)$ & 2500 \\
Average hours of sunlight $\left(\mathrm{hr} \mathrm{day}^{-1}\right)$ & 6.4 \\
Total irradiated receiver area $\left(\mathrm{m}^{2}\right)$ & 1579 \\
Capacity factor & 0.43 \\
Power block efficiency $\left(\right.$ at $\left.540{ }^{\circ} \mathrm{C}\right)$ & 0.4 \\
\hline
\end{tabular}

\subsection{Annualized energy production}

\subsubsection{Degradation profile}


The annualized energy production is directly affected by receiver characteristics, in particular the coating properties. Aging of solar absorbers is mostly characterized by the evolution of their solar absorptance. Currently, there is no standard method that can predict the degradation behavior of these coatings, and existing aging data are very sparse. An obstacle in variable condition aging is the determination of a timescale in which degradation can be quantified. Under ambient conditions where aging mechanisms act continuously, real time can be a fair indicator of the age of the object considered. In CSP, the strong variations of temperature and multiple intermittent aging mechanisms involved make real time a poor age indicator. For instance, a power plant operating 5 hours a day may have a longer real lifetime than a plant operating 10 hours a day, and yet be less durable regarding its in-operation (or "service") lifetime.

The US Department of Energy (DOE) SunShot Initiative set a 30 year lifetime objective for 2020 but also added a 10,000 cycle objective (equivalent to 27.4 years assuming 1 cycle a day) in an attempt to provide an alternative to real time quantification of durability. However, the US DOE did not provide the context of these numbers in spite of the wide variety of conditions in which receivers may work. For example, more than 200+ solar irradiance cycles of at least $100 \mathrm{~W} \mathrm{~m}^{-2}$ are easily reachable during a cloudy day [22]. 10,000 of these cycles would only represent a lifetime of 50 cloudy days. This illustrates the difficulty, yet the necessity, to develop reliable durability indicators for CSP components. In order to estimate and compare the service lifetime of receivers on a more rigorous basis, we propose to project aging on the "on-sun" timescale instead of the power generation or real timescales. Receiver aging resulting of dark phases (nights, clouds, maintenance, etc.) and radiative/thermal cycling is taken into account but reported on the closest "on-sun" time as an instantaneous degradation. Assuming an average sunlight time of 6.4 hours per day (Las Vegas, NV) and a plant lifetime $S L=30$ years (in real time), the "on-sun" service lifetime $S L_{o s}$ is calculated to be 8 years, if no other downtime is assumed.

In order to assess the influence of coating degradation on the absolute LCOC, different possible degradation profiles are considered for the solar absorptance. For specific coatings with available degradation profiles and costs, accurate absolute LCOC values can be calculated by simply including these experimental data in the model. If no experimental data is available, the presented approach is to consider multiple possible costs and degradation profiles and then analyze their effects on the LCOE via absolute LCOC calculations. The Arrhenius law is often used as a degradation profile when aging is driven by chemical reactions and temperature. In CSP solar receivers, the high temperature variations and concurrent aging mechanisms make the Arrhenius law inapplicable. Instead, a new model function is introduced that is based on the observation that aging in CSP is typically represented by a globally decelerating decreasing solar absorptance that might show local drops. The degradation profile is built from the function: $f(\mathrm{z})=\arctan (-\mathrm{az})$ where $\mathrm{a} \in \mathbb{R}+$ represents the slope of the degradation and $\mathrm{z} \in \mathbb{R}$ is analog to a time variable. This function is selected for its ability to represent a decelerated, accelerated, intermediate or linear decrease between two values, depending on a small number of parameters (five). Their influence on the absolute LCOC is investigated.

The solar absorptance degradation profile is constructed as follows: the time domain $\left[z_{1}, z_{2}\right]$ is selected such as $z_{1} \leq 0$ and $z_{2} \geq 0$, corresponding to the initial and final times $t_{0}$ and $t_{S L}$ of the "on-sun" life of the receiver, respectively. The section of $f$ inside the domain is used to define the "shape" of the degradation profile. It is possible to show that all possible "shapes" can be obtained on the domain $\left[x_{1}, x_{2}\right]$, where $x_{1} \in[-1,0], x_{2} \in[0,1]$ and $x_{2}-x_{1}=1$, as long as the coefficient $a$ is modified accordingly: $f(z)=\arctan (-A x)$ where $A=a\left(z_{2}-z_{1}\right)$ and $x=z /\left(z_{2}-z_{1}\right)$. The degradation "shape" is thus fully defined by $x_{1}$ and $A$ (see illustration in Figure 2). If $x_{1}=0$, the highest degradation slope is located at the beginning of the time 
domain (early degradation); if $\mathrm{x}_{1}=-1$, the highest degradation slope is at the end of the domain (late degradation); if $x_{1}=-0.5$, the highest degradation slope is observed at the center of the domain (intermediate degradation). The definition of the degradation profile is completed by setting the initial and final solar absorptance values $\alpha_{0}$ and $\alpha_{S L}$, corresponding (but not equal) to $f\left(x_{1}\right)$ and $f\left(x_{2}\right)$, as well as the "on-sun" service lifetime of the receiver $S L$. Finally, the solar absorptance function $\alpha_{S}\left(t_{o s}\right)$ is expressed in the form $\alpha_{S}\left(t_{o s}\right)=a \arctan \left(b t_{o s}+c\right)+d$ where (eq 5):

$$
a=\frac{\left(\alpha_{0}-\alpha_{S L}\right)}{\arctan \left(A x_{2}\right)-\arctan \left(A x_{1}\right)} \quad b=\frac{A\left(x_{1}-x_{2}\right)}{S L_{o s}} \quad c=-A x_{1} \quad d=\frac{\left(\alpha_{0}-\alpha_{S L}\right) \arctan \left(A x_{2}\right)}{\arctan \left(A x_{2}\right)-\arctan \left(A x_{1}\right)}+\alpha_{S L}
$$

where $t_{o s}$ is the "on-sun" time and $S L_{o s}$ is the "on-sun" service lifetime of the plant. The degradation profile is defined by setting $x_{1}, A, \alpha_{0}, \alpha_{S L}$ and $S L$. Figure 3 shows a degradation profile example defined by $x_{1}=-0.4, A=5, \alpha_{0}=0.97, \alpha_{S L}=0.85$ and $S L_{o s}=8$ years. The degradation profile is applied to the whole receiver area as an average solar absorptance although the coating's optical properties may vary locally in a discontinuous fashion. The solar absorptance of materials may vary with temperature. The degradation profiles considered represent the solar absorptance at a nominal surface temperature of the receiver $T_{\text {nom }}$. The final absorptance value can be conveniently chosen equal to the oxidized metal substrate if the coating eventually consumes or delaminates. Mechanical failure of the receiver is not considered in this paper.

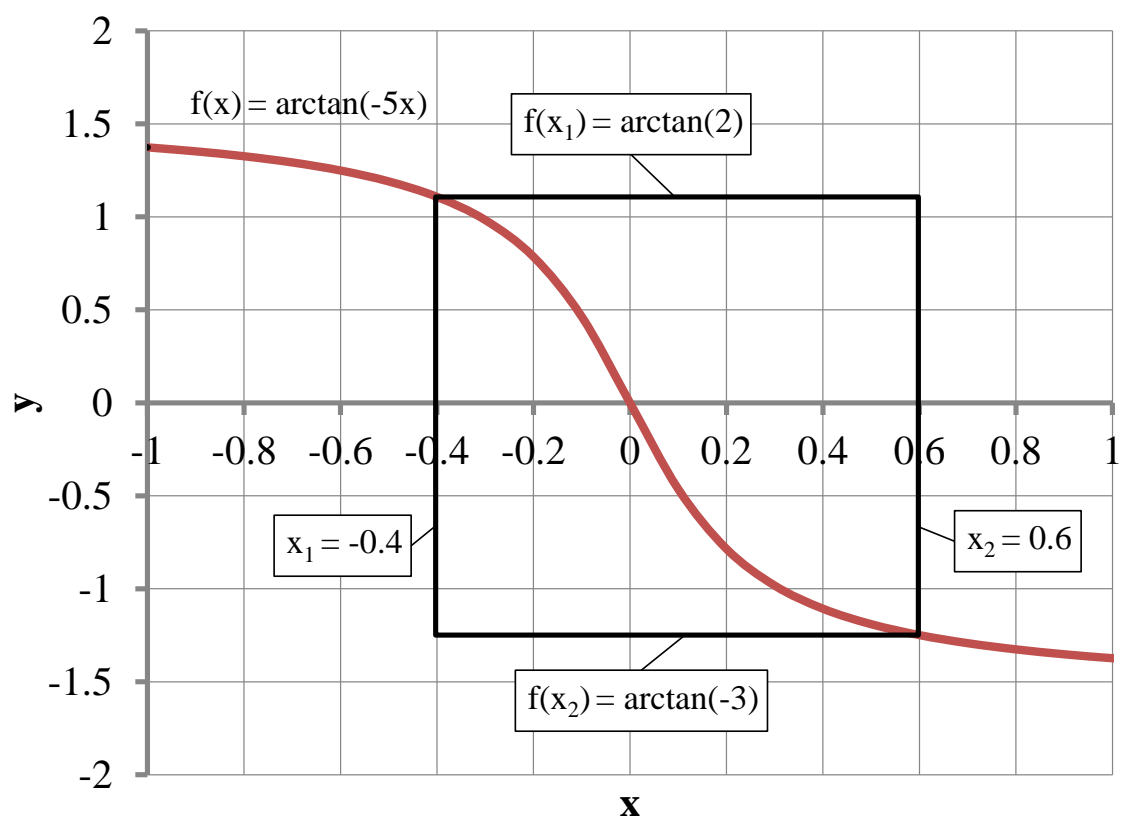

Figure 2. Demonstration of function $f(x)=\arctan (-A x)$ with $x_{1}=-0.4$ and $A=5$. The black frame shows the selected domain. The constant $A$ is small $\left(\sim 10^{-1}\right)$ to simulate a linear degradation, or high $\left(\sim 10^{3}\right)$ for a sudden degradation. 


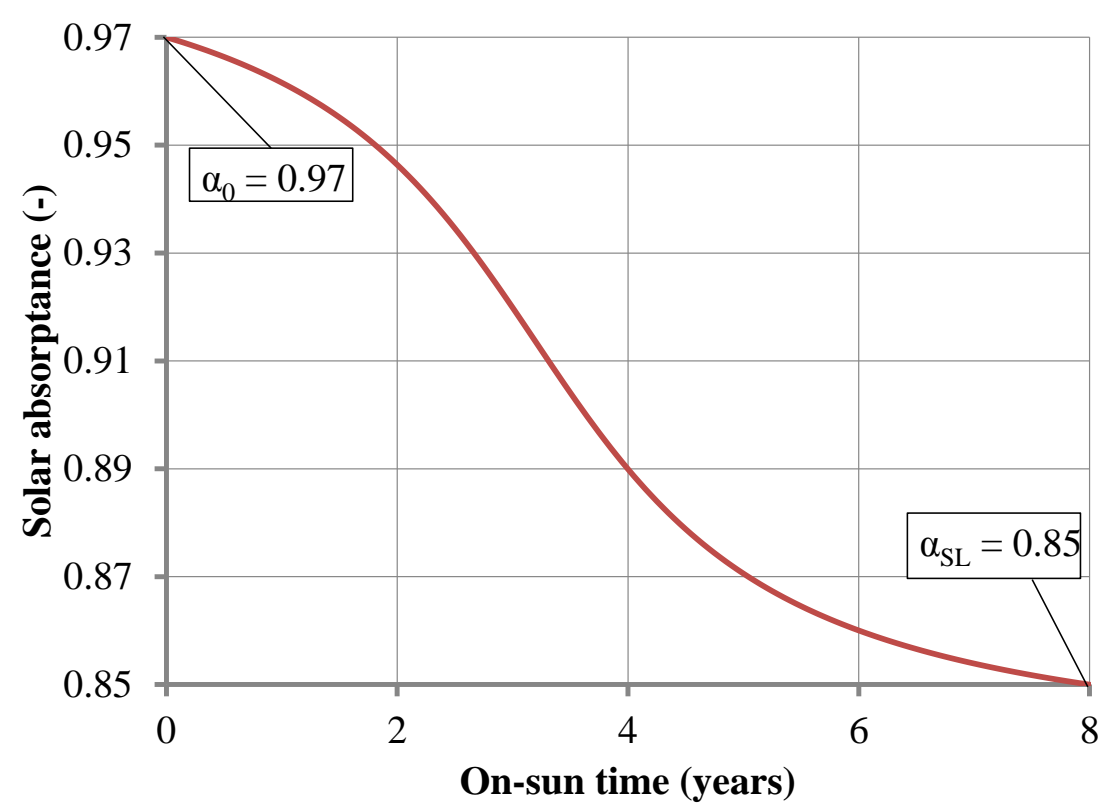

Figure 3. Solar absorptance degradation profile with $x_{1}=-0.4, A=5, \alpha_{0}=0.97, \alpha_{S L}=0.85$, and $S L_{o s}=8$ years.

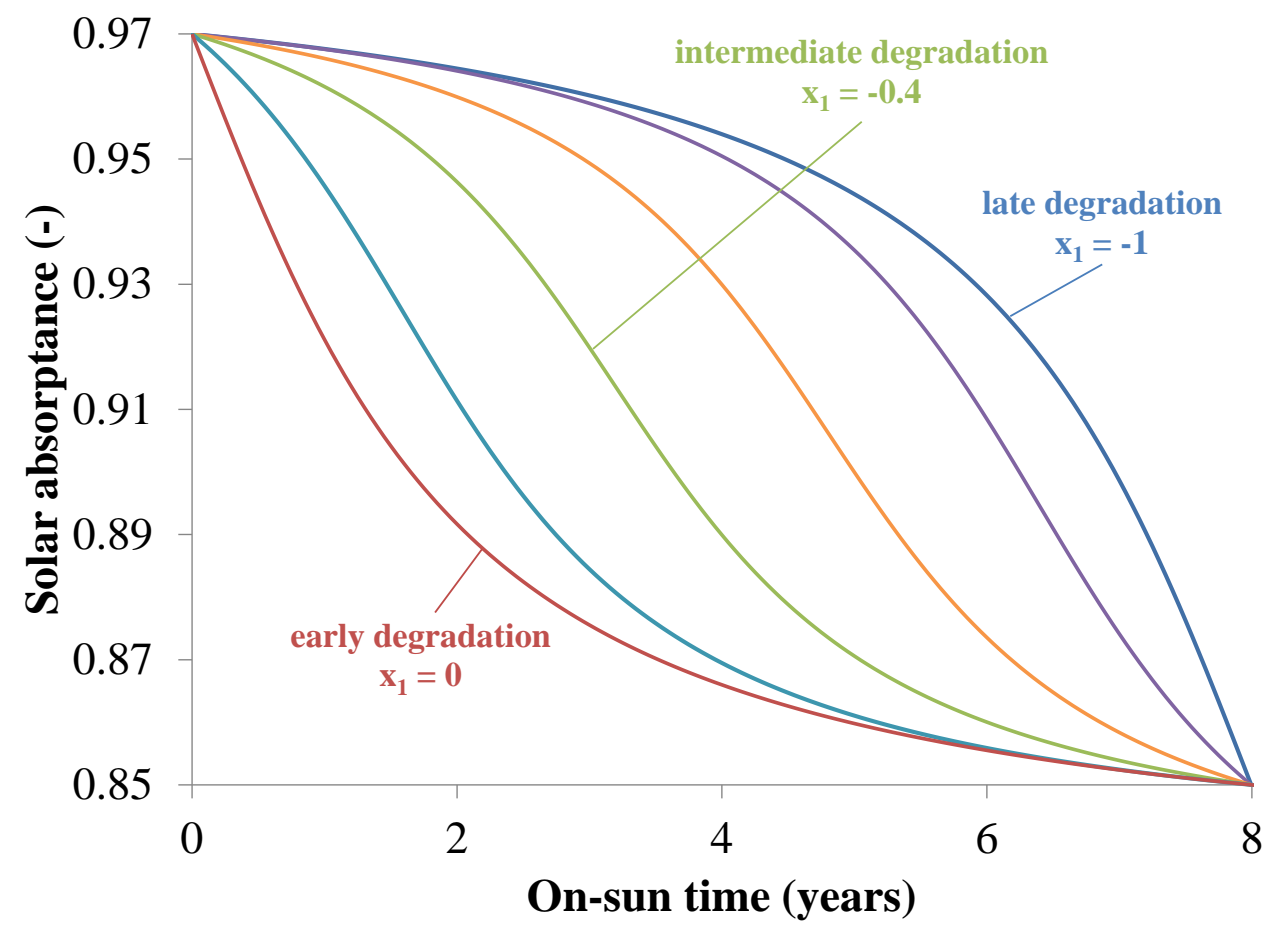

(a) Early $\left(x_{1}=0\right)$, intermediate $\left(x_{1}=-0.5\right)$ and late $\left(x_{1}=-1\right)$ degradation profiles with same degradation constant $A=5$ 


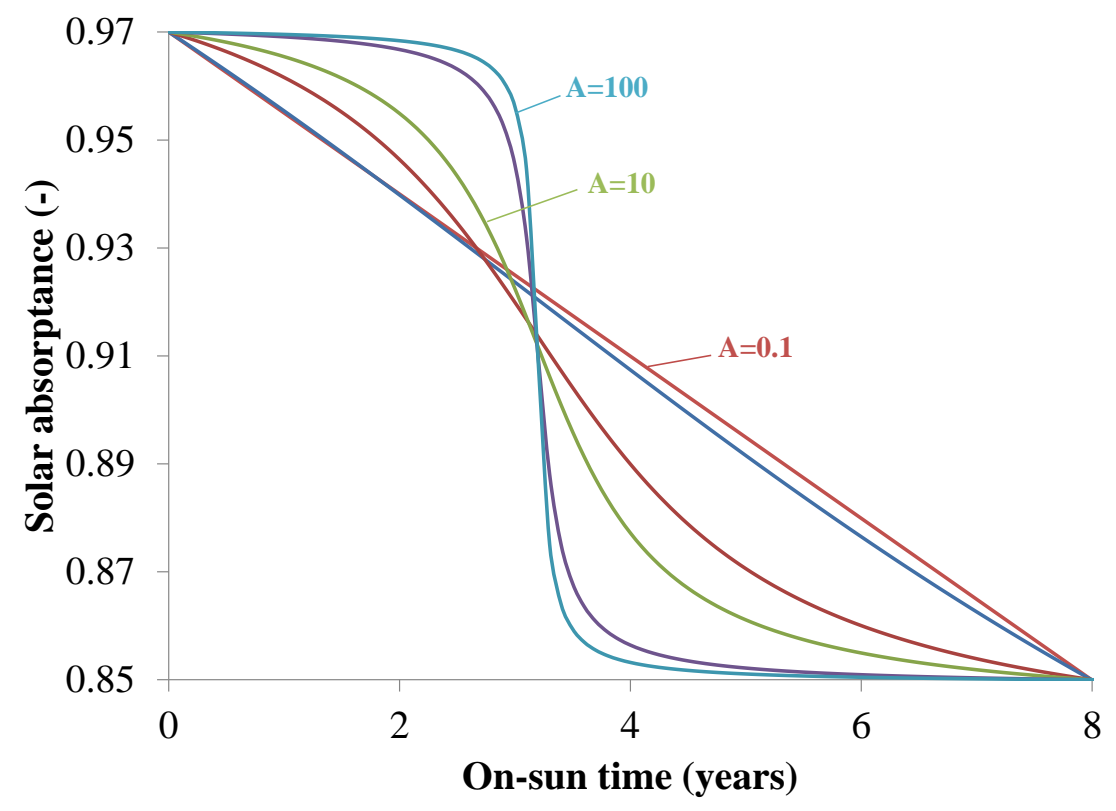

(b) Intermediate degradation profiles $\left(x_{1}=-0.4\right)$ with degradation constant $A$ varying from 0.1 to 100

Figure 4. Degradation profiles for various "shapes" (a) and degradation constant values (b). $\alpha_{0}=0.97$, $\alpha_{S L}=0.85, S L_{o s}=8$ years.

The "shape" of the degradation profile is adjusted by $x_{1}$. The slope of the degradation is controlled by $A$, $\alpha_{0}, \alpha_{S L}$, and $S L_{o s}$. Figure 4 shows different solar absorptance models with (Figure 5 (a)) several "shapes" and same degradation constant $(A=5)$, and (Figure $5(b))$ several values of the degradation constant $A$ for the same "shape" $\left(x_{1}=-0.4\right)$.

\subsubsection{Reapplication Interval $(R I)$ and Downtime $(D T)$}

When the coating degrades, the absorbed energy decreases. After a given period of time, a reapplication of a new coating is generally carried out by the plant operator to recover the initial performance and maintain a minimum power output. This leads to additional costs and generally, temporary shutdown of the receiver during the recoating process.

From this perspective, we introduce two variables: the reapplication interval, $R I$, which is the number of years between two consecutive coating applications; and the downtime, $D T$, which is the number of days the receiver is not irradiated for the recoating process. $R I_{o s}$ is defined as the equivalent "on-sun" reapplication interval. It is assumed that the receiver recovers its initial absorptance after each reapplication, and that the coating follows the same degradation behavior after reapplication (same degradation profile). The higher the number of reapplications, the longer the total downtime, and the shorter the "on-sun" time. The reapplication interval is assumed the same during the service lifetime of the plant. Figure 5 shows the hypothetical solar absorptance of a coating (considering the intermediate 
degradation presented in Figure 3) with a reapplication interval of 10 years (1 initial application +2 reapplications in 30 years) and a reapplication downtime of 15 days.

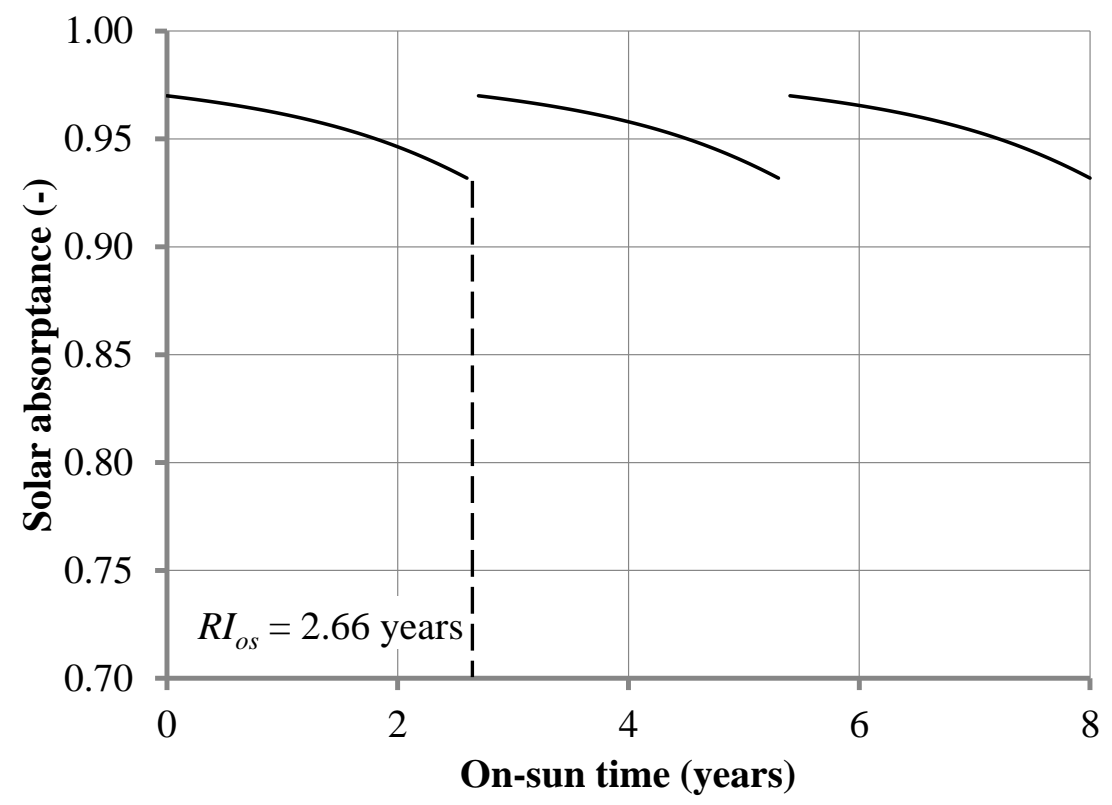

Figure 5. Intermediate degradation profile with a reapplication interval $R I=10$ years and a downtime $D T=15$ days. $x_{1}=-0.4, A=5, \alpha_{0}=0.97, \alpha_{S L}=0.85, S L=30$ years. Taking into account the

$2 \times 15=30$ day downtime necessary for reapplication, the "on-sun" reapplication interval is 2.66 years and the "on-sun" service lifetime $S L_{o s}$ is 7.97 years.

\subsubsection{Expression of the annualized energy}

The annualized electricity production $E_{e}$ depends on multiple factors such as the solar tower design, the location, the power block, and the receiver characteristics. $E_{e}$ is calculated by integration over the plant's service lifetime, which is also equal to the annualized energy produced over the "on-sun" reapplication interval (eq. 6):

$$
E_{e}=\frac{\eta_{e} E_{i}}{R I_{o s}} \int_{0}^{R I_{o s}} \eta_{t h} d t_{o s}
$$

where $E_{i}$ is the annualized incident solar energy on the receiver, $\eta_{e}$ is the power block efficiency which is temperature-dependent and assumed $62.5 \%$ of the Carnot cycle efficiency $\left(\eta_{e}=0.625 \times\left(1-T_{\text {air }} / T_{\text {nom }}\right)\right) . \eta_{\text {th }}$ is the receiver efficiency which depends on the degradation profile $\alpha_{S}$.

The energy absorbed by the receiver is affected by the evolution of the thermal efficiency. Previous studies $[20,22]$ showed that the aging of the coating is mainly represented by the evolution of the solar 
absorptance. For this reason, the thermal emittance is assumed constant and the following simplified expression of the receiver efficiency is used (eq. 7):

$$
\eta_{\text {th }}\left(t_{\text {os }}\right)=\frac{\alpha_{S}\left(t_{\text {os }}\right) \Phi_{i, n o m}-\varepsilon \sigma S T_{\text {nom }}{ }^{4}-h S\left(T_{\text {nom }}-T_{\text {air }}\right)}{\Phi_{i, n o m}}
$$

Where $\Phi_{i, n o m}$ is the nominal incident solar power, $\sigma$ is the Stefan-Boltzmann constant, $S$ is the external surface area of the receiver, $T_{n o m}$ is the nominal surface temperature $\left(T_{\text {nom }}=813 \mathrm{~K}\right), h$ is the convection coefficient in $\operatorname{air}\left(h=20 \mathrm{~W} \mathrm{~m}^{-2} \mathrm{~K}^{-1}\right)$ and $T_{\text {air }}$ is the air temperature $\left(T_{\text {air }}=293 \mathrm{~K}\right) . \varepsilon$ is the thermal emittance. The annual electrical output expression is (eq. 8):

$$
E_{e}=\eta_{e} E_{i}\left(\eta_{t h, 0}-\alpha_{0}+d+\frac{a}{b R I_{o s}}\left(\left(b R I_{o s}+c\right) \arctan \left(b R I_{o s}+c\right)+\frac{1}{2} \ln \left(\frac{\left(1+c^{2}\right)}{1+\left(b R I_{o s}+c\right)^{2}}\right)-c \arctan (c)\right)\right) \quad \text { (eq. }
$$

Maintaining high absorptance while limiting the reapplication costs is a trade-off which is optimized by the number of reapplications.

\subsection{Annualized costs}

The LCOE implicitly depends on plant specific variables such as power capacity, technology, and location. Identical coatings may have different absolute LCOC values from one plant to another. Thus, special attention needs to be paid to the context in which absolute LCOC values are compared. In the following, the influence of the coating on the absolute LCOC is studied by changing a single parameter at a time, keeping the others at their nominal values.

\subsubsection{Cost of the coating}

Coating costs vary depending on the material and coating technology used. During the receiver lifetime, the coating may be reapplied several times in order to maintain high efficiency. In this case, other expenses may be added depending on the recoating techniques employed and whether the receiver needs to be taken apart or not.

Initial costs and reapplication costs are taken into account and annualized. We identified the following categories of expenses:

- Preparation of coating

- Preparation of substrate

- Application of coating

- Other treatments (ex: curing) 
- Quality assurance

For each category, we distinguish three subcategories of costs: materials, equipment, and labor.

Depending on the accuracy needed, other categories can be added to take into account other significant sources of expenses (transportation, safety, etc.).

In the study, initial and reapplication costs of $\$ 500 \mathrm{k}$ and $\$ 250 \mathrm{k}$ are assumed, respectively. In section 4.2, the absolute LCOC is investigated for various costs up to \$1 M per (re-)application.

\subsubsection{Cost of the plant}

The absolute LCOC quantifies the contribution of the coating to the LCOE. As a thorough estimation of the cost of every plant component would be fastidious and tied with large uncertainties, the cost of the plant is calculated via an average LCOE of today's solar power plants: $\$ 210 \mathrm{MW}_{\mathrm{e}}^{-1} \mathrm{hr}^{-1}$ [23]. This is equivalent to a total annualized cost of $\$ 79,147,950 \mathrm{yr}^{-1}$.

In section 4.5, we also study the absolute LCOC in a futurist scenario considering an annualized cost of $\$ 22,613,700 \mathrm{yr}^{-1}$. This value corresponds to an LCOE of $\$ 60 \mathrm{MW}_{\mathrm{e}}^{-1} \mathrm{hr}^{-1}$ which is the targeted LCOE for 2020 set by the U.S. Department of Energy SunShot Initiative [23].

\section{Results}

\subsection{Influence of the coating degradation, reapplication interval and downtime}

The absolute LCOC of a non-selective coating is first calculated with reapplication intervals from 0.1 to 30 years by step of 0.1 year. The "shape" and the degradation constant $A$ are varied separately. The reference LCOE is calculated considering no coating (bare metal). The assumed properties of the coating and metal are shown in Table 2.

Table 2. Initial and final optical properties of the metal and the non-selective coating considered

\begin{tabular}{ccc}
\hline & $\begin{array}{c}\text { Reference: Metal } \\
(\text { ex: Inconel 625) }\end{array}$ & $\begin{array}{c}\text { Coating: non-selective } \\
\text { (ex: Pyromark 2500) }\end{array}$ \\
\hline $\boldsymbol{\alpha}_{\boldsymbol{0}}$ & 0.85 & 0.97 \\
$\boldsymbol{\alpha}_{S L}$ & 0.85 & 0.85 \\
$\boldsymbol{\varepsilon}_{\boldsymbol{0}}$ & 0.60 & 0.85 \\
$\boldsymbol{\varepsilon}_{S L}$ & 0.60 & 0.85 \\
\hline
\end{tabular}

An electric output of 340,371 MW h yr${ }^{-1}$ is calculated for the uncoated receiver. This yields a reference LCOE of 79,147,950 / 340,371 $\approx 232.5 \mathrm{MW}^{-1} \mathrm{~h}^{-1}$. 
The absolute LCOC of the coating is then calculated. Figure 6 shows the absolute LCOC map function of the reapplication interval for different degradation shapes (late, intermediate, early) and same degradation constant $(A=10)$. The minimum absolute LCOC for each degradation profile is plotted in purple. This curve indicates the optimal reapplication interval for each degradation profile.

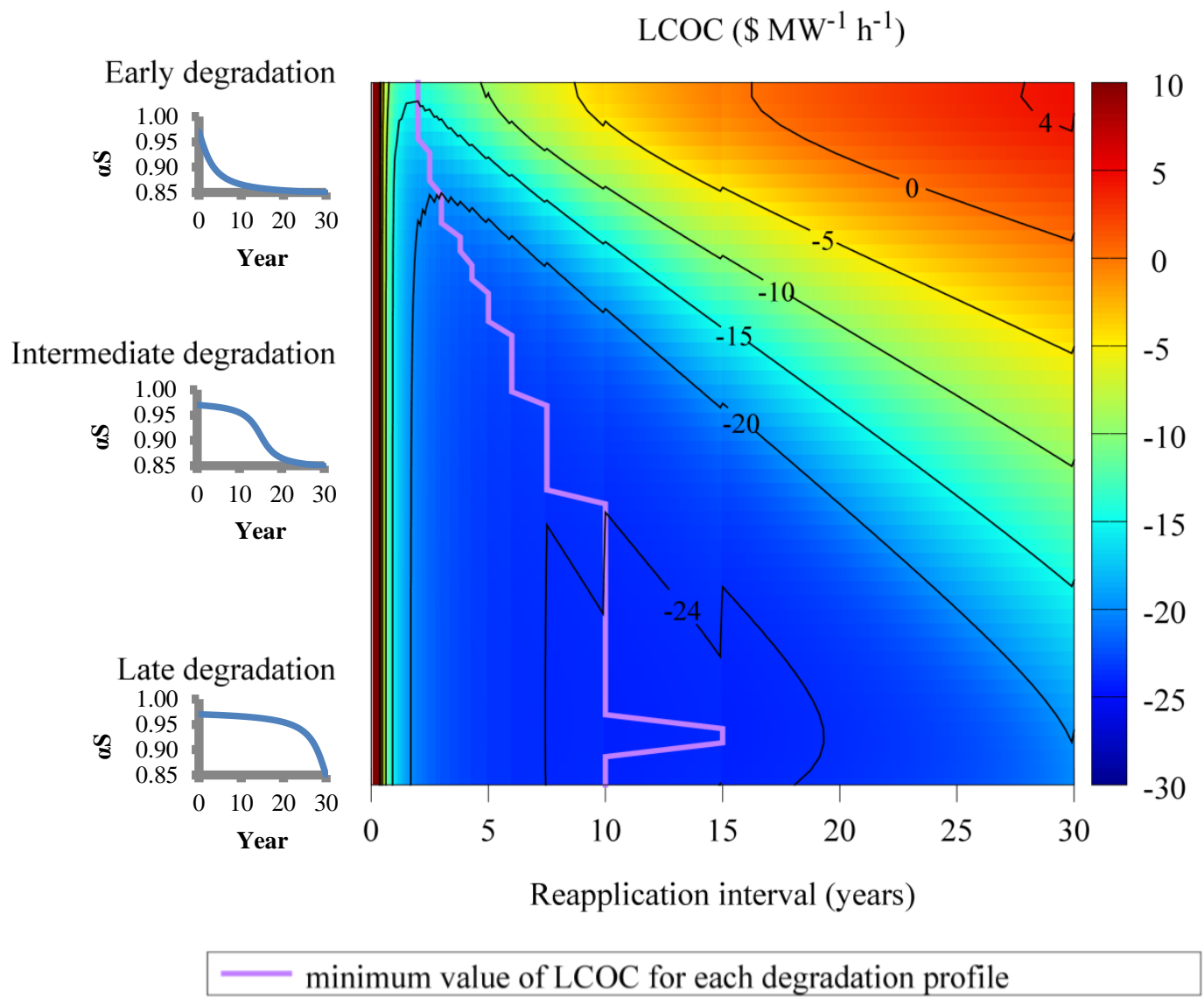

Figure 6. Absolute LCOC as a function of the reapplication interval and the degradation shape with a late $\left(x_{1}=-1\right)$ to early degradation profile $\left(x_{1}=0\right) . A=10, D T=15$ days, $S L=30$ years, $L C O E_{\text {ref }}=\$ 232.5 \mathrm{MW}^{-1} \mathrm{~h}^{-1}$

We observe a region of high absolute LCOC values for early degradations and long reapplication intervals (> 15 years), and low LCOC values for a late degradation and a reapplication interval between 7.5 to 19 years. Negative values of the absolute LCOC show an improvement due to the coating (lower LCOE). Positive values of the absolute LCOC represent an LCOE higher than the receiver without coating (bare metal). A zero value means no change in the LCOE due to the coating. It is profitable to use the coating only when the predicted absolute LCOC is negative.

If the coating degradation is very late, we observe that it is possible to lower the reference LCOE by $\$ 24.4 \mathrm{MW}^{-1} \mathrm{~h}^{-1}$, which represents a $10 \%$ reduction — relative to the reference LCOE — accountable to the coating. We observe that for an intermediate degradation, the coating still results in decreasing the LCOE, as long as the reapplication interval is less than 15 years (at least one reapplication necessary over the 
receiver lifetime). The minimum absolute $\mathrm{LCOC}$ for each degradation profile (curve in purple in Figure 6) indicates that it is possible to find an optimal reapplication interval for each degradation profile. A single reapplication at halfway through the plant lifetime is recommended if the coating degrades late or very slowly. For intermediate and early degradation profiles, the optimal reapplication interval decreases to 2.5 years. The observed discontinuities or "switchbacks" are generated by the fact that any reapplication that would be required at the end of the plant lifetime is avoided. Example: a reapplication interval of 14 years would lead to two reapplications: at 14 and 28 years, whereas an interval of 15 years would only lead to a single reapplication at 15 years, the second reapplication falling at the end of the service lifetime of the receiver.

To assess the influence of the degradation constant $A$ and the downtime $D T$, the absolute LCOC is plotted on Figure 7 for $A$ from 0.1 to 100 , an early degradation $\left(x_{1}=0\right)$, and two downtimes: 15 days and 1 day.

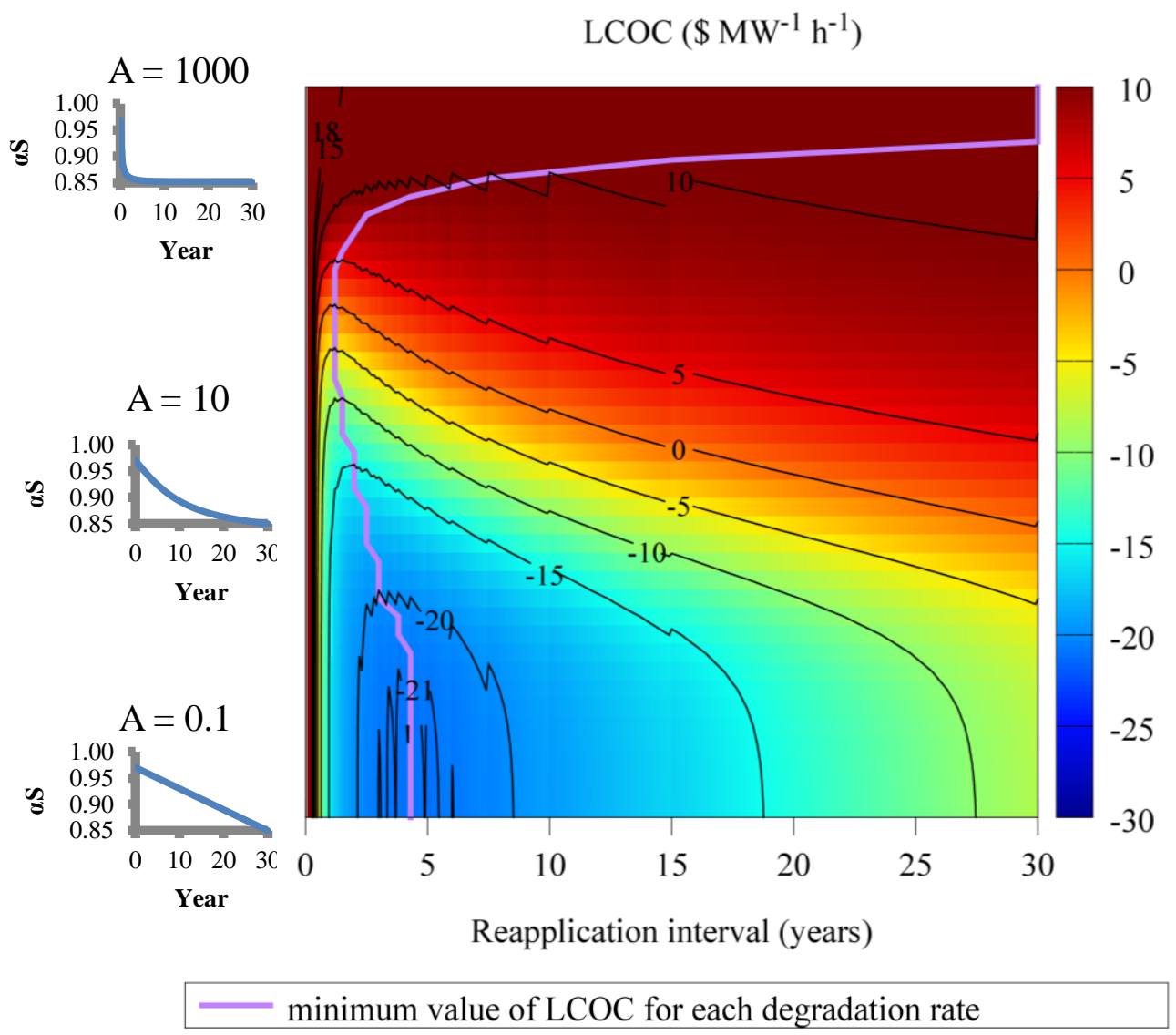

(a) Downtime of 15 days for reapplication 


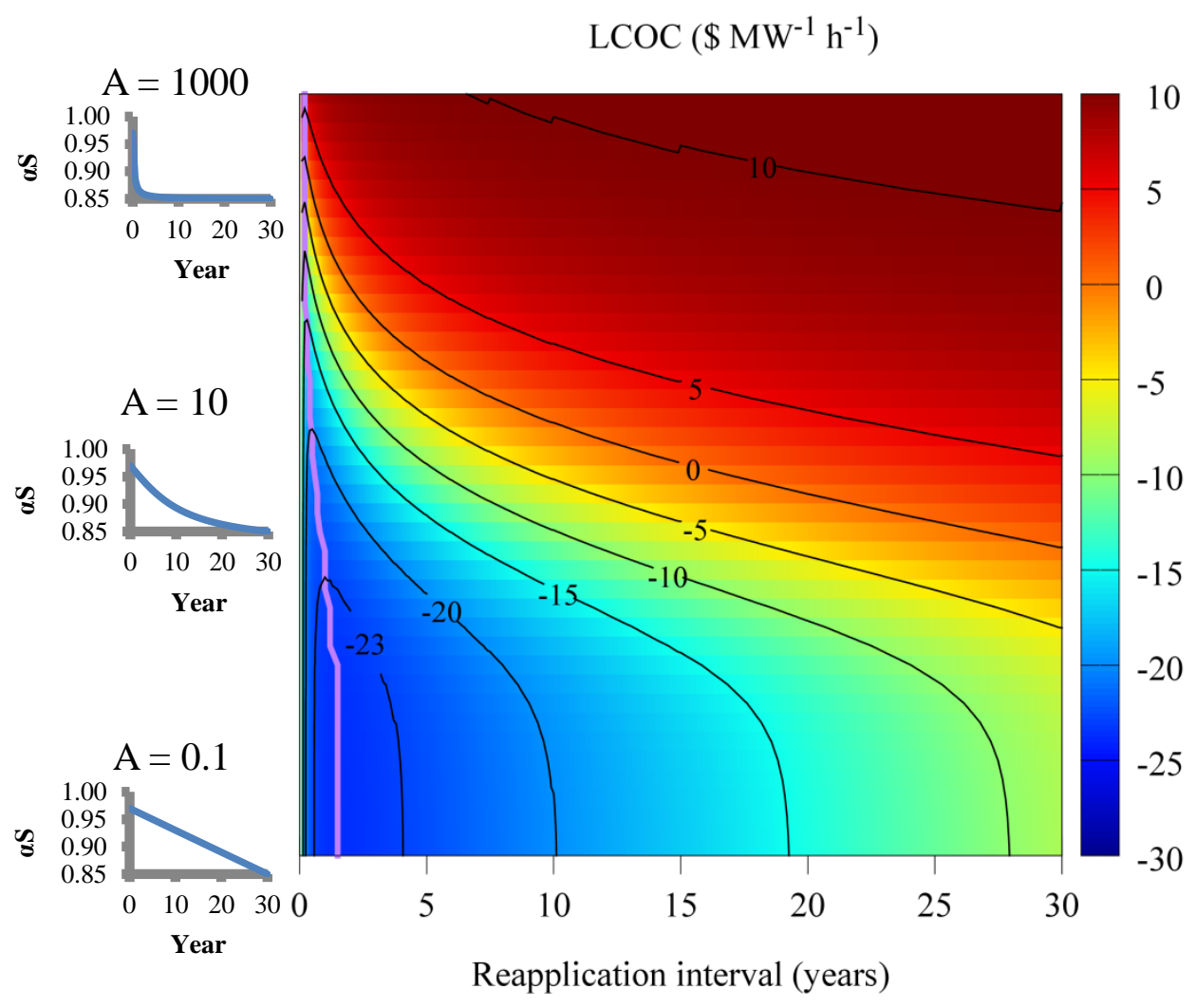

minimum value of LCOC for each degradation rate

(b) Downtime of 1 day for reapplication

Figure 7. Absolute LCOC as a function of the reapplication interval and the degradation constant $A$ for an early degradation profile with (a) $D T=15$ days and (b) $D T=1$ day. $A$ from 0.1 to $1000, x_{1}=0, S L=30$ years, $L C O E_{\text {ref }}=\$ 232.5 \mathrm{MW}^{-1} \mathrm{~h}^{-1}$

The degradation constant significantly affects the absolute LCOC. For an early catastrophic degradation $(A \geq 1000)$, the absolute LCOC is greater than $\$ 10.4 \mathrm{MW}^{-1} \mathrm{~h}^{-1}$ and rapidly increases with shorter reapplication intervals and faster degradations. For a near-linear degradation $(A=0.1)$, a value of $-\$ 21.3 \mathrm{MW}^{-1} \mathrm{~h}^{-1}$ is reached for a reapplication interval of 3 to 6 years and a downtime of 15 days. If a process enables a one-day downtime for recoating, the minimum value of the absolute LCOC decreases to $-\$ 23.8 \mathrm{MW}^{-1} \mathrm{~h}^{-1}$ which is a $-\$ 2.5 \mathrm{MW}^{-1} \mathrm{~h}^{-1}$ improvement compared to a 15 -day downtime. The optimal reapplication interval also decreases. For a linear degradation profile, a reapplication interval of 4.5 years is recommended in the case $D T=15$ days, but only 1.4 year if $D T=1$ day. As the degradation constant increases to high values, the optimal reapplication interval falls below one month and the absolute LCOC becomes positive. In most cases, the coating presence decreases the LCOE as long as the reapplication interval ranges between 1 and 5 years. 


\subsection{Influence of the initial coating and reapplication costs}

In this section the influence of the initial coating and reapplication costs is analyzed. The absolute LCOC of a non-selective coating is calculated depending on its initial and reapplication costs in two opposite cases: (a) a late degradation with $A=1000$ and a reapplication interval of 4.5 years; and (b) an early degradation with $A=1000$ and a reapplication interval of 1 year. Case (a) tends to reduce the influence of the coating costs while Case (b) tends to enhance it. Cost ranges from $\$ 0$ to $\$ 1 \mathrm{M}$ per application.

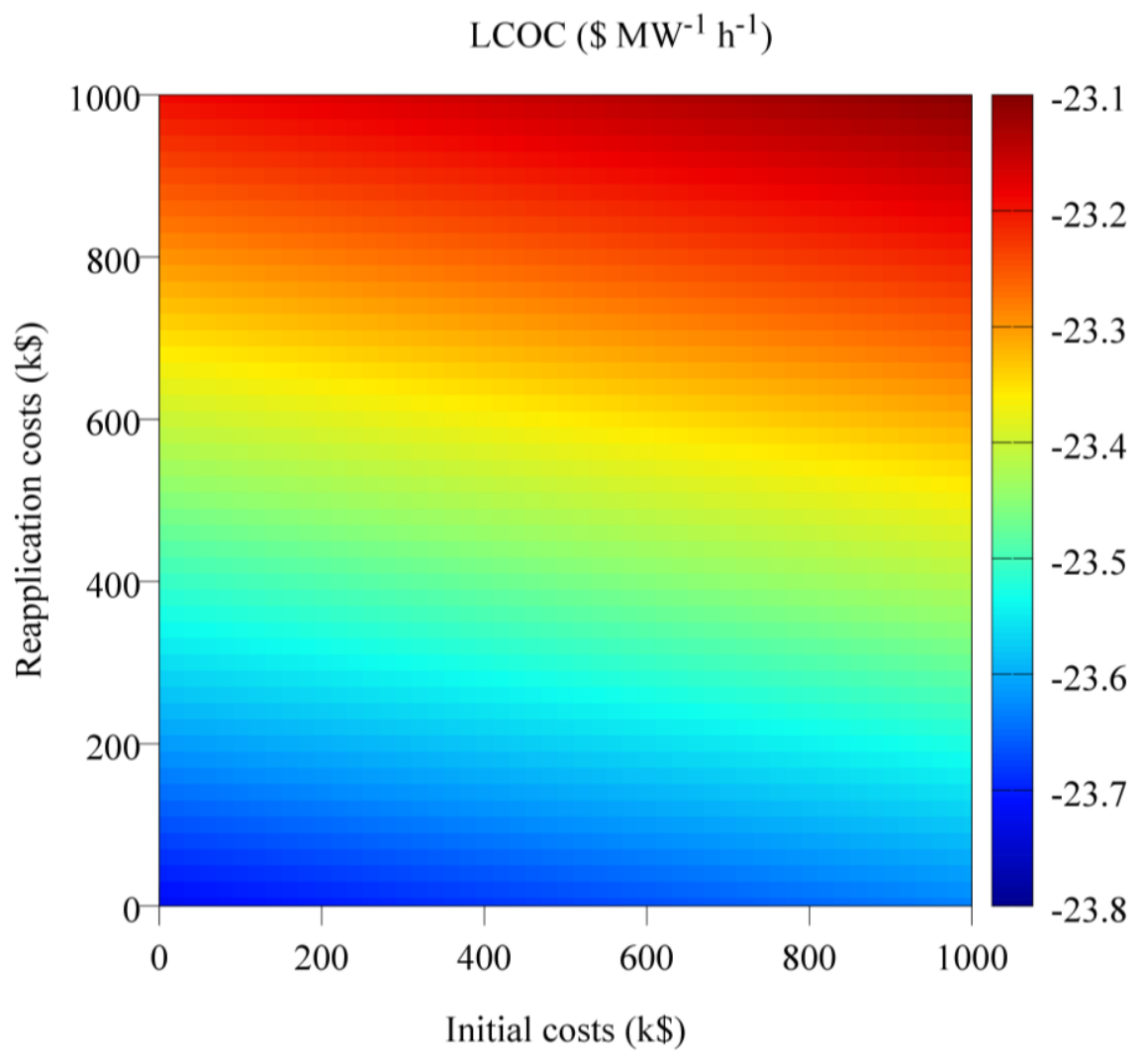

(a) $x_{1}=-1, R I=4.5$ years 


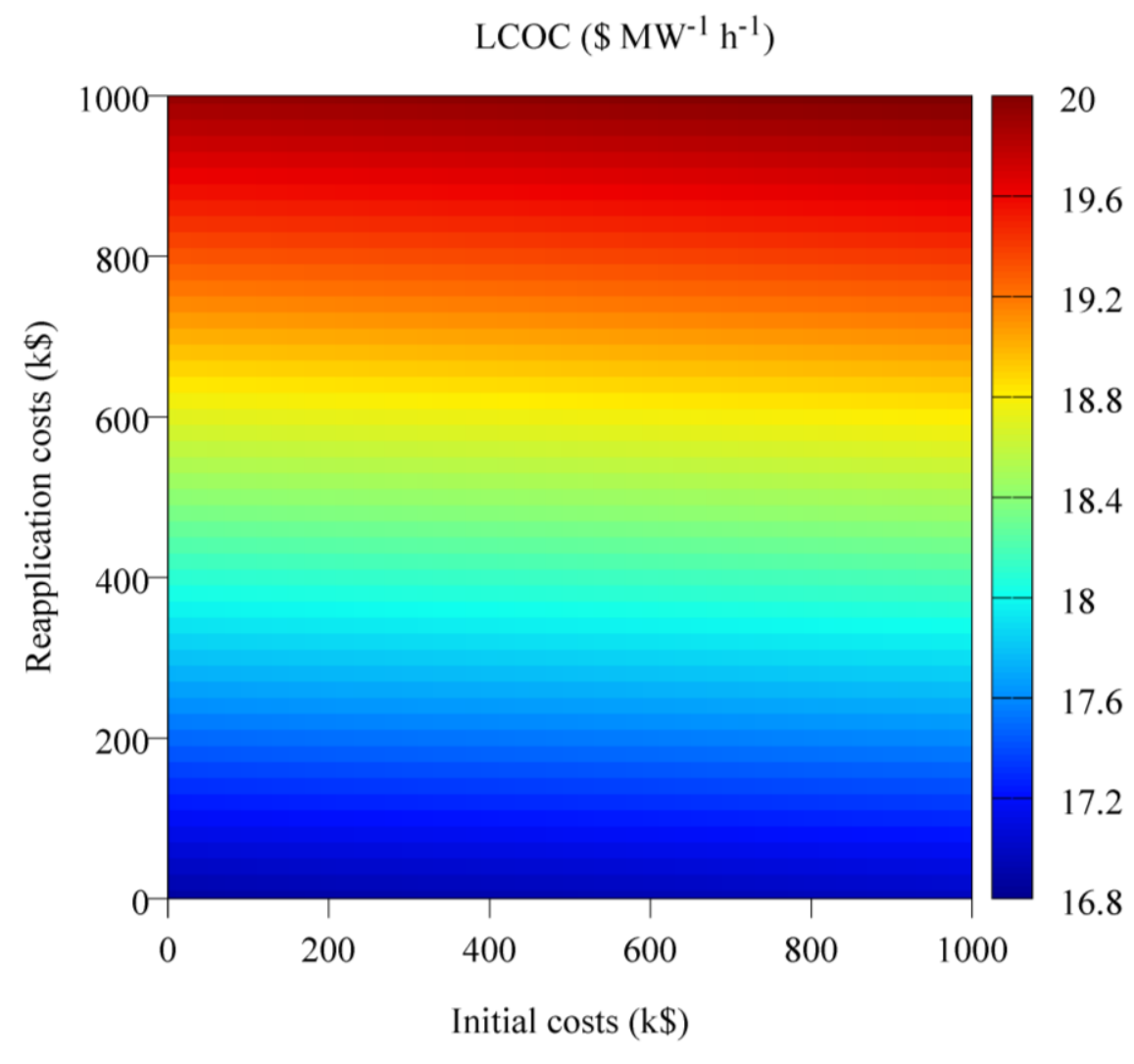

(b) $x_{1}=0, R I=1$ year

Figure 8. Absolute LCOC as a function of the initial and reapplication costs for a reapplication interval of 1 year and (a) a late degradation and a reapplication interval of 4.5 years (b), an early degradation profile. $A=1000, D T=15$ days, $S L=30$ years, $L C O E_{\text {ref }}=\$ 232.5 \mathrm{MW}^{-1} \mathrm{~h}^{-1}$

Figure 8 (a) shows very small influence of the coating costs on the absolute LCOC. Costs of $\$ 1 \mathrm{M}$ per application/reapplication only increase the absolute LCOC of $\$ 0.7 \mathrm{MW}^{-1} \mathrm{~h}^{-1}$. Figure 8 (b) also shows relatively low sensitivity of the absolute LCOC to the costs even though their influence is enhanced in this case. A difference of $\$ 3.2 \mathrm{MW}^{-1} \mathrm{~h}^{-1}$ is observed between the maximum and minimum values. In both cases, the reapplication costs have more influence than the initial costs. However, as a general result, the coating costs should not affect the LCOE more than $\$ 3 \mathrm{MW}^{-1} \mathrm{~h}^{-1}$ in the cost range investigated. Thus, the absolute LCOC can be considered less sensitive to the cost of the coating than to its degradation. This can be better comprehended by noticing that the coating cost is generally very small compared to the total cost of the plant while a gain in the energy output impacts directly the LCOE of the plant.

\subsection{Solar selective coating}


The effect of using a selective coating instead of a non-selective coating is studied. The initial application and reapplication costs are unchanged (500 $\mathrm{k} \$$ and $250 \mathrm{k} \$$ respectively). Only the assumed optical properties are different, notably the thermal emittance: $\alpha_{0}=0.95, \alpha_{S L}=0.85, \varepsilon_{0}=0.60$, and $\varepsilon_{S L}=0.60$.

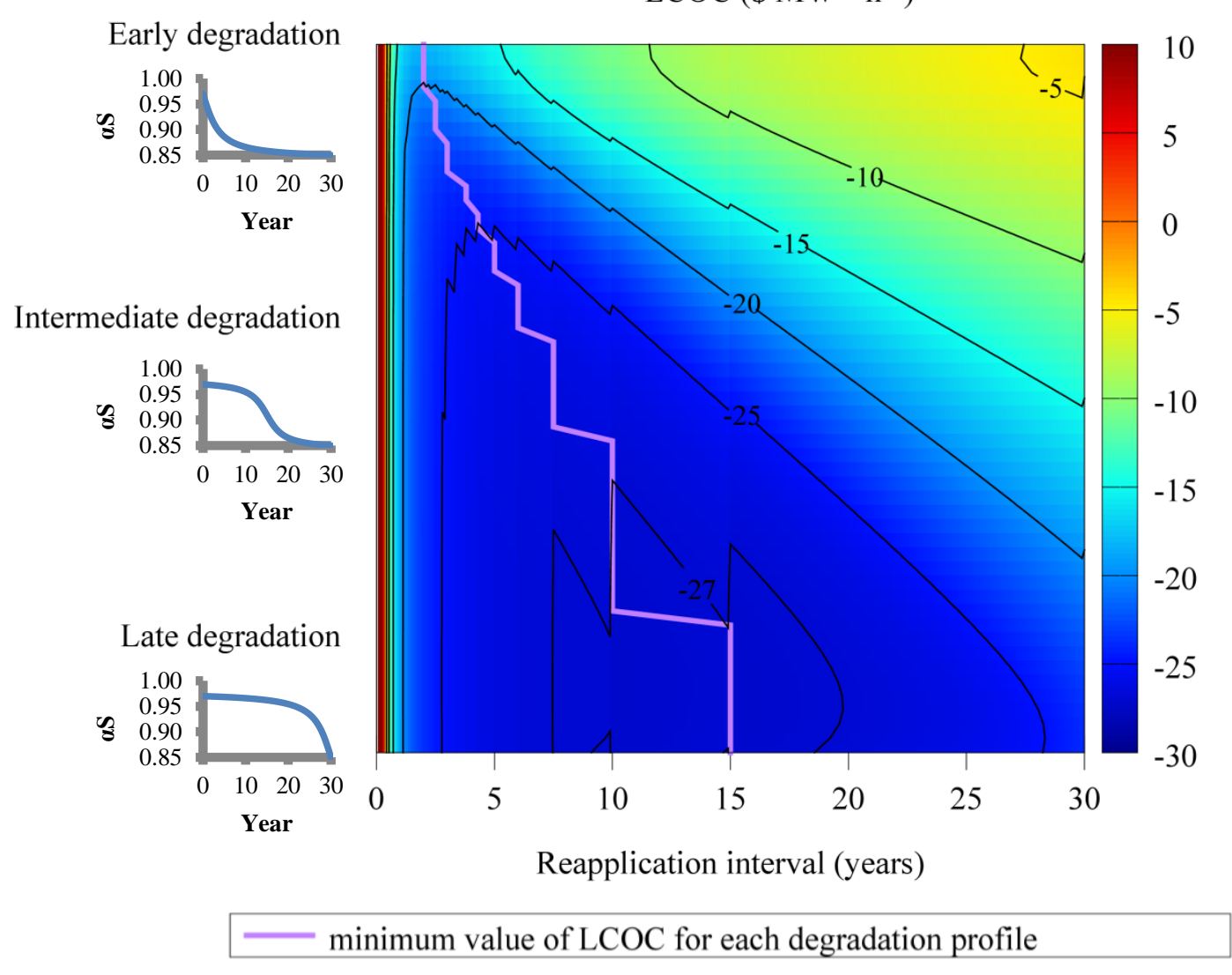

Figure 9. Absolute LCOC as a function of the reapplication interval and the degradation shape. Selective coating, $D T=15$ days, $A=10, S L=30$ years, $L C O E_{\text {ref }}=\$ 232.5 \mathrm{MW}^{-1} \mathrm{~h}^{-1}$

Figure 9 shows the absolute LCOC map obtained depending on the degradation profile and the reapplication interval. We observe that the use of such a selective coating would always be worthwhile as it only results in negative absolute LCOC values (lower LCOE) for the degradation profiles studied. The minimum improvement in this case is $\$ 4.6 \mathrm{MW}^{-1} \mathrm{~h}^{-1}$ lower than the reference LCOE, and increases above $\$ 27 \mathrm{MW}^{-1} \mathrm{~h}^{-1}$ for a late degradation and reapplication interval of 7.5 to 19 years. The minimum absolute LCOC value of $-\$ 27.4 \mathrm{MW}^{-1} \mathrm{~h}^{-1}$ represents an $11.8 \%$ gain on the reference LCOE due to the coating. This is also a $\$ 3.0 \mathrm{MW}^{-1} \mathrm{~h}^{-1}$ improvement compared to the minimum absolute LCOC of a nonselective coating in the same conditions $\left(-\$ 24.4 \mathrm{MW}^{-1} \mathrm{~h}^{-1}\right)$.

\subsection{Influence of the receiver temperature}


A change in the receiver surface temperature affects the coating by changing its properties, generating different aging mechanisms, and increasing the thermal losses. It also modifies the power block efficiency whether the receiver is coated or not. This is why the absolute LCOC is calculated taking into account the variation of the reference LCOE of the plant due to temperature. The absolute LCOC is plotted for both the non-selective (Figure 10) and selective coatings (Figure 11) as a function of the reapplication interval and the nominal receiver temperature $T_{\text {nom }}$ in the range $400{ }^{\circ} \mathrm{C}-800{ }^{\circ} \mathrm{C}$ assuming an early degradation profile with $A=10$.

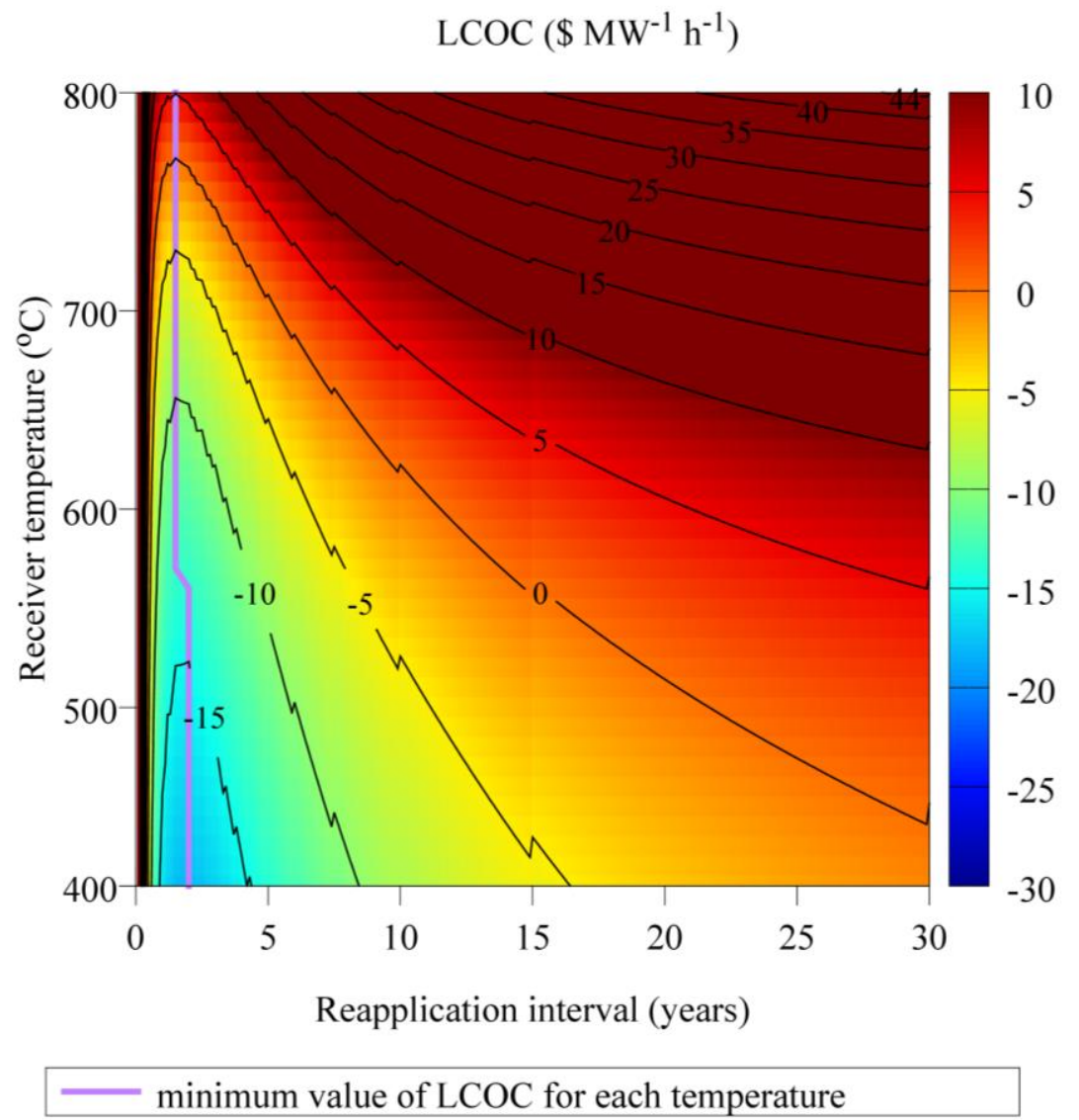

Figure 10. Absolute LCOC as a function of the nominal receiver temperature and reapplication interval for a non-selective coating. $x_{1}=0, A=10, D T=15$ days, $S L=30$ years 


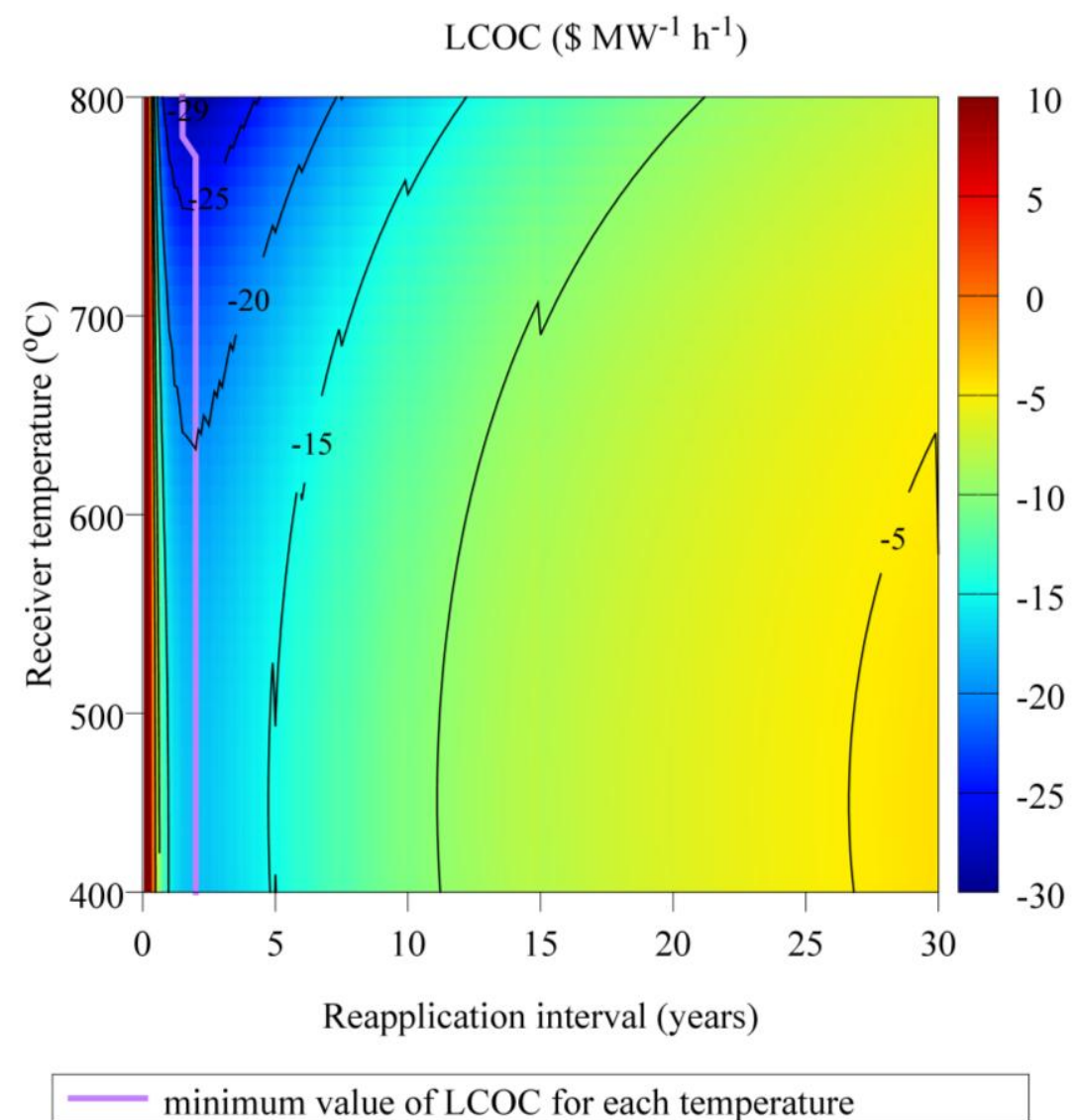

Figure 11. Absolute LCOC as a function of the nominal receiver temperature and reapplication interval. Selective coating, $\mathrm{A}=10, x_{1}=0, \mathrm{DT}=15$ days $S L=30$ years 


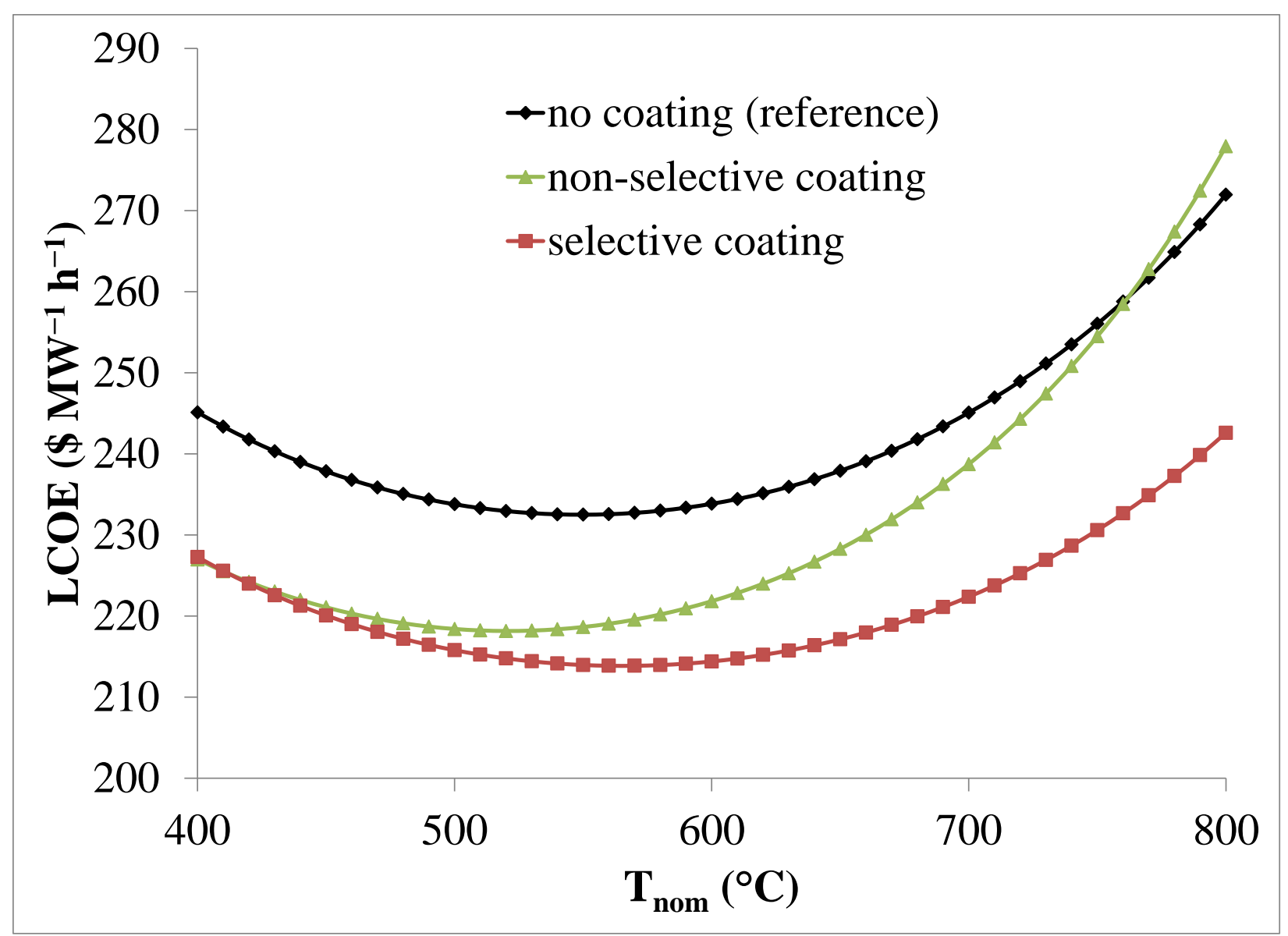

Figure 12. LCOE of a non-selective and selective coating with $R I=2$ years as a function of the receiver nominal temperature

The absolute LCOC of a non-selective coating globally increases with the receiver temperature. This is due to the decrease in the thermal efficiency at higher temperature, caused by higher radiative and convective thermal losses. Values lower than $-\$ 16.0 \mathrm{MW}^{-1} \mathrm{~h}^{-1}$ are reachable for temperatures lower than $530{ }^{\circ} \mathrm{C}$. At $800{ }^{\circ} \mathrm{C}$, a minimum value of $\$ 5.1 \mathrm{MW}^{-1} \mathrm{~h}^{-1}$ is reached for $R I=1.5$ years. The receiver temperature does not significantly affect the optimal reapplication interval which is 2 years in the range $400{ }^{\circ} \mathrm{C}-580{ }^{\circ} \mathrm{C}$ and 1.5 year up to $800{ }^{\circ} \mathrm{C}$.

In the case of the selective coating, the lower thermal emittance (0.6 instead of 0.85$)$ reduces the effect of the receiver temperature on the thermal losses at high temperature. The absolute LCOC is negative which means it is worthwhile to apply such a coating regardless of the temperature and degradation, in the conditions investigated. It is worth noticing that - as opposed to the non-selective coating case - the lowest absolute LCOC values are observed at higher temperature. This behavior can be explained by higher power block efficiency at higher temperature; as well as a smaller ratio between the thermal losses and the absorbed power, compared to the bare metal receiver case. At $T_{n o m}=800{ }^{\circ} \mathrm{C}$ and $R I=1.5$ years, the absolute LCOC is $-\$ 29.4 \mathrm{MW}^{-1} \mathrm{~h}^{-1}$. The optimal reapplication interval of $1.5-2.0$ years is quasiindependent of the receiver temperature. 
Figure 12 shows the calculated LCOE of the non-selective and selective coatings for a reapplication interval of 2 years, compared with the temperature-dependent reference LCOE. The reference LCOE is minimum for $T_{\text {nom }}=550{ }^{\circ} \mathrm{C}$ of $\$ 232.5 \mathrm{MW}^{-1} \mathrm{~h}^{-1}$. Low power block efficiency at lower temperatures and high thermal losses at higher temperatures result in higher values on either side. The non-selective coating has a minimum LCOE of $\$ 218.2 \mathrm{MW}^{-1} \mathrm{~h}^{-1}$ for $T_{\text {nom }}=520^{\circ} \mathrm{C}$ whereas the selective coating minimum is $\$ 213.9 \mathrm{MW}^{-1} \mathrm{~h}^{-1}$ for $T_{n o m}=570{ }^{\circ} \mathrm{C}$. For temperatures greater than $700{ }^{\circ} \mathrm{C}$, the selective coating maintains a low LCOE while the non-selective coating reaches and passes the reference LCOE at about $770{ }^{\circ} \mathrm{C}$.

Three important statements can be drawn from this analysis:

- the lowest absolute LCOC value does not necessarily correspond to the lowest LCOE when $L C O E_{\text {ref }}$ is not constant.

- the selective coating enables larger decrease in the absolute LCOC at higher temperature but offers negligible benefits at $T_{\text {nom }}=400{ }^{\circ} \mathrm{C}$

- at $800^{\circ} \mathrm{C}$, it is preferable not to apply any coating than applying the non-selective coating

\subsection{Future cost reduction}

To take into account improvement of CSP technologies and the expected reduction of costs in the coming years, achievement of U.S. Department of Energy SunShot Initiative goals [23] is assumed. In particular, the total cost of the plant is assumed at $\$ 22,613,700 \mathrm{yr}^{-1}$, which corresponds to an average LCOE of $\$ 60 \mathrm{MW}_{\mathrm{e}}^{-1} \mathrm{hr}^{-1}$ for the plant considered. With this cost and considering the properties of the uncoated receiver (Table 2), the reference LCOE is $\$ 66.4 \mathrm{MW}_{\mathrm{e}}^{-1} \mathrm{hr}^{-1}$.

Figure 13 shows the absolute LCOC of a selective coating $\left(\alpha_{0}=0.95, \alpha_{S L}=0.85, \varepsilon_{0}=0.60\right.$, and $\left.\varepsilon_{S L}=0.60\right)$ for different degradation shapes and constant values assuming a reduced plant cost. 


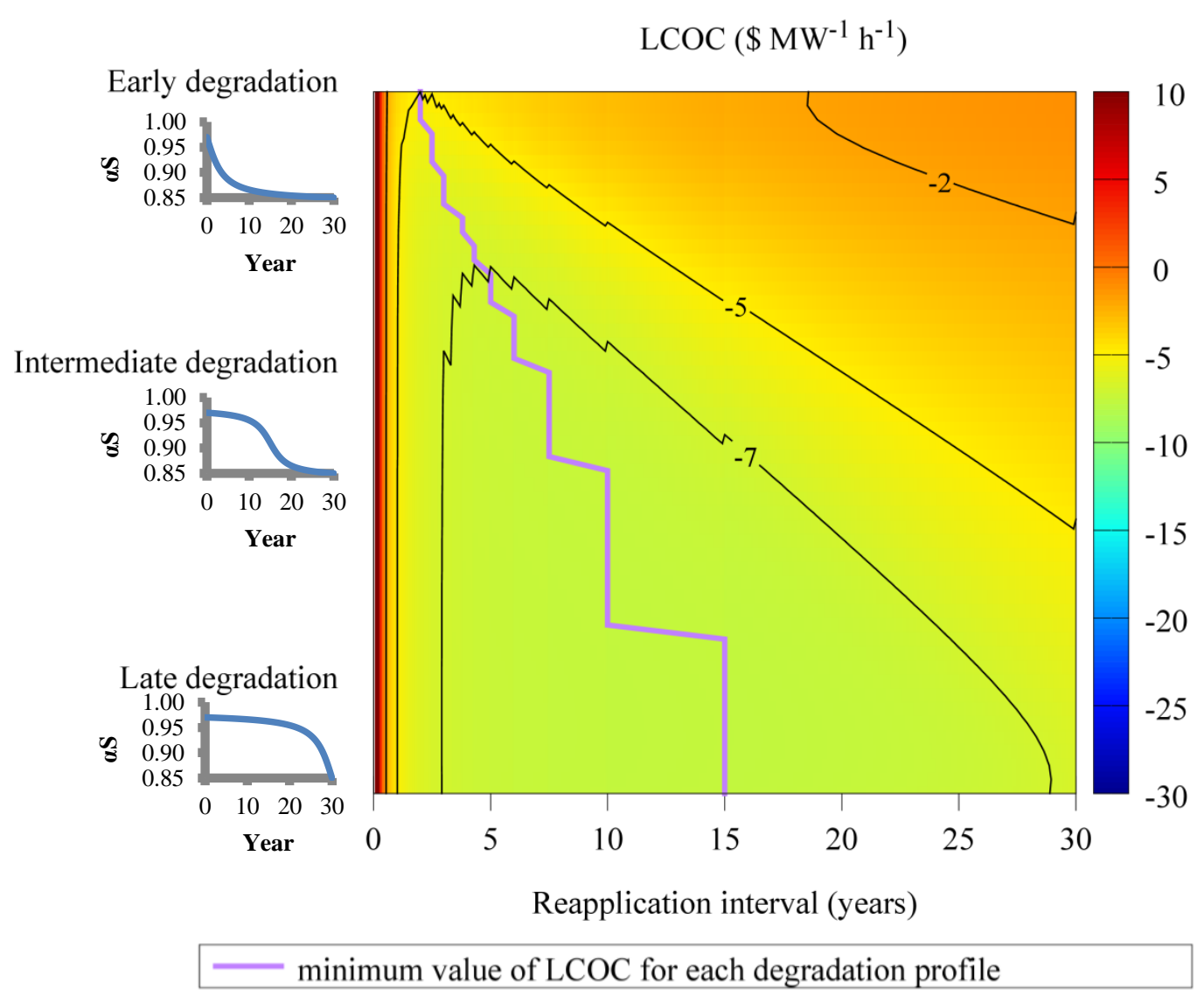

(a) $x_{1}$ from -1 to $0, A=10$ 


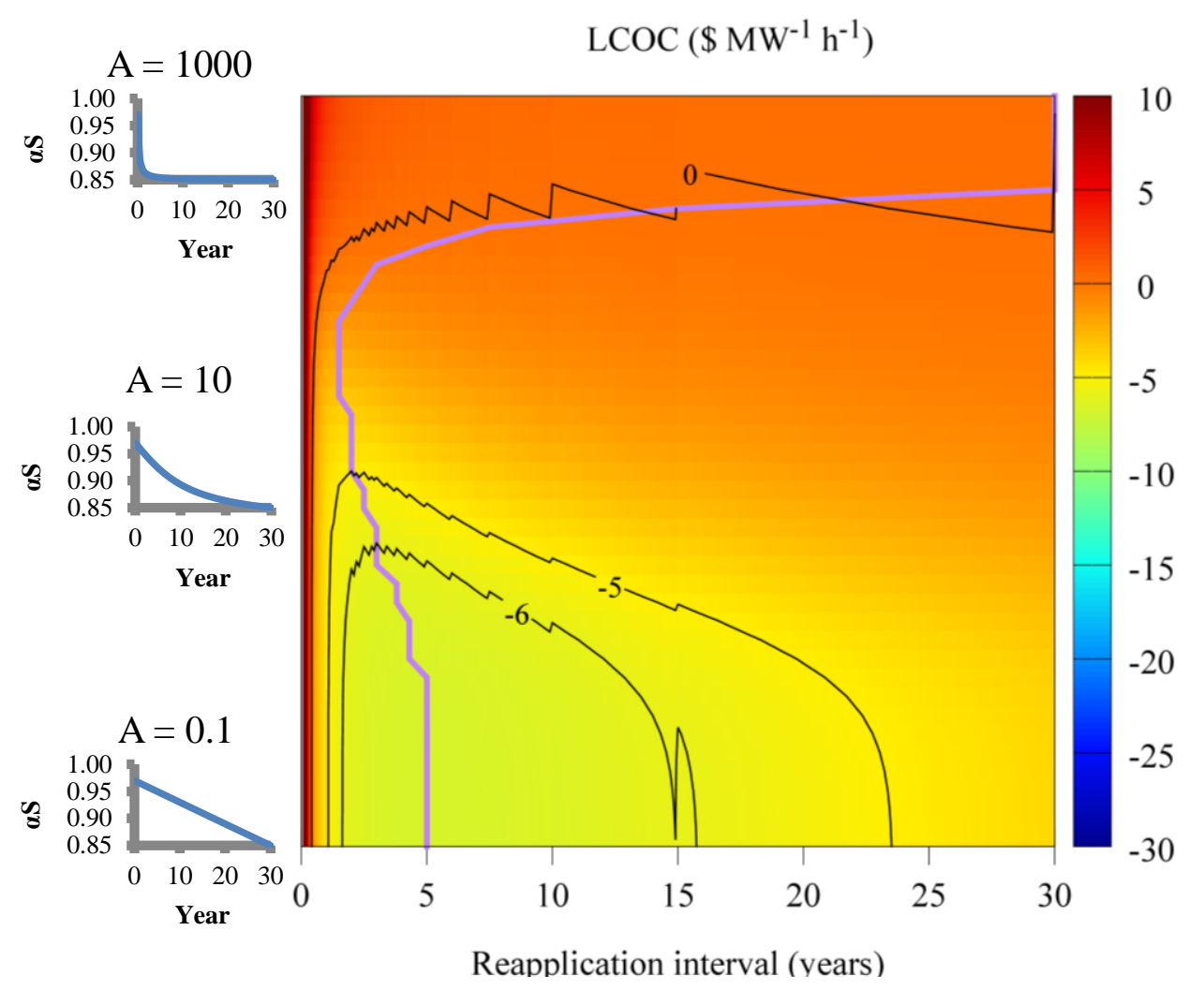

minimum value of LCOC for each degradation rate

(b) $x_{1}=0, A$ from 0.1 to 1000

Figure 13. Absolute LCOC as a function of the reapplication interval and the degradation profile. Selective coating, $D T=15$ days, $S L=30$ years, $L C O E_{\text {ref }}=\$ 66.4 \mathrm{MW}^{-1} \mathrm{~h}^{-1}$

The minimum absolute LCOC for a late degradation is about $-\$ 7.8 \mathrm{MW}_{\mathrm{e}}^{-1} \mathrm{hr}^{-1}$ which brings the LCOE down to $\$ 58.6 \mathrm{MW}_{\mathrm{e}}^{-1} \mathrm{hr}^{-1}$. This represents a decrease of $11.7 \%$ of the reference LCOE. We observe that for a late to intermediate degradation, the reapplication interval does not have a strong influence on the LCOC. When varying the degradation constant of an early degradation profile, we observe that the absolute LCOC is minimized at $-\$ 6.9 \mathrm{MW}_{\mathrm{e}}^{-1} \mathrm{hr}^{-1}$ with a reapplication interval of 3 to 5 years. At high degradation constant, the absolute LCOC is positive.

This scenario shows that the coating could participate in the achievement of the SunShot LCOE target of $\$ 60 \mathrm{MW}_{\mathrm{e}}^{-1} \mathrm{hr}^{-1}$ with a reduction of the LCOE ranging between $0 \%$ and $12 \%$. Assuming a similar scenario but with an ideal coating $\left(\alpha_{0}=1, \alpha_{S L}=1, \varepsilon=0\right)$ available at no cost with an infinite durability (i.e. no degradation), the absolute LCOC would be $-\$ 15.8 \mathrm{MW}_{\mathrm{e}}^{-1} \mathrm{hr}^{-1}$. Taking the minimum absolute LCOC value of a selective coating in the futurist scenario presented in Figure 13 (b) $\left(-\$ 7.8 \mathrm{MW}_{\mathrm{e}}^{-1} \mathrm{hr}^{-1}\right)$, the "LCOC efficiency" is $-7.8 /-15.8=49 \%$. 


\subsection{Absolute LCOC of Pyromark 2500 paint}

Pyromark 2500 is a refractory black paint used in solar tower receivers. It has a high solar absorptance (up to 0.97 ) but is poorly selective, which means its thermal emittance is also high ( 0.85). It is made to withstand high temperatures (up to $1000^{\circ} \mathrm{C}$ ) but degrades faster at temperatures greater than $600^{\circ} \mathrm{C}$ and under radiative cycles. It has been used in several receivers since solar tower Solar One, and is considered today as a reference coating for tower receivers. Table 3 shows an estimation of the initial and reapplication coating costs for Pyromark 2500. These estimations are rough and do not reflect any real bill of materials. The purpose is to demonstrate application of the absolute LCOC.

Table 3. Estimated initial and reapplication costs of Pyromark 2500. The reapplication costs assume reuse of some of the equipment purchased for the initial application.

\begin{tabular}{lrrl}
\hline Task & $\begin{array}{l}\text { Initial Costs } \\
\text { (USD) }\end{array}$ & $\begin{array}{l}\text { Reapplication Costs } \\
\text { (USD) }\end{array}$ & Comments \\
\hline Preparation of coating & $\mathbf{2 6 8 0 4}$ & $\mathbf{2 5 3 0 4}$ & \\
Materials & 12804 & 12804 & Pyromark + solvent \\
Equipment & 2000 & 500 & Containers, cleaning, misc. \\
Labor & 12000 & 12000 & 3 people, 1 week \\
\hline Preparation of substrate & $\mathbf{3 7 6 3 5}$ & $\mathbf{2 8 1 3 5}$ & \\
Materials & 7896 & 7896 & Sand $\$ 5$ per m $^{2}$ \\
Equipment & 10000 & 500 & Sandblasting rig, scaffolding equipment, \\
Labor & 19739 & safety gears, consumables, etc. \\
\hline Application of coating & $\mathbf{2 4 7 3 9}$ & 19739 & 3 people, $1 / 8$ h per m ${ }^{2}$ \\
Materials & 0 & $\mathbf{2 0 2 3 9}$ & \\
Equipment & 5000 & 0 & \\
Labor & 19739 & 500 & spray guns, misc. \\
\hline Curing and other treatments & $\mathbf{1 1 2 0 0 0}$ & 19739 & 3 people, $1 / 8$ h per m ${ }^{2}$ \\
Materials & 0 & $\mathbf{1 2 5 0 0}$ & \\
Equipment & 100000 & 0 & \\
Labor & 12000 & 500 & Custom oven \\
\hline Quality assurance, & 12000 & 3 people, 1 week \\
performance monitoring & $\mathbf{1 1 2 0 0 0}$ & $\mathbf{7 7 0 0}$ & \\
Materials & 0 & 0 & \\
Equipment & 50000 & 500 & Measurement devices, cameras, \\
Labor & 12000 & 7200 & 3 people, 1 week \\
\hline TOTAL & $\mathbf{2 6 3 1 6 8}$ & & \\
\hline
\end{tabular}

The annualized initial costs are $263,168 / 30=\$ 8,772 \mathrm{yr}^{-1}$. The annualized costs for each reapplication are $93,878 / 30=\$ 3,129 \mathrm{yr}^{-1}$. 
The absolute LCOC of Pyromark 2500 is calculated depending on the reapplication interval. The lifetime of the plant is assumed to be 30 years. To determine the degradation profile we use aging data of the Solar One receiver [24]. During its operation, it was reported that Pyromark had rapidly degrading performance with an initial solar absorptance value $\alpha_{0}=0.92$ and an initial slope of $-0.1038 \mathrm{yr}^{-1}$. After reapplication of a new layer at $t_{o s}=0.70$ years, the paint showed higher absorptance $\alpha_{0}=0.97$ and lower degradation slope of $-0.0482 \mathrm{yr}^{-1}$, as shown in Figure 14. The poor quality of the first coating application was never clearly explained but might have been caused by improper preparation or curing treatment.

To investigate what would be the influence of these two coatings on the absolute LCOC, we first extrapolate corresponding early degradation profiles from the initial degradation slopes shown above to an assumed final absorptance value of 0.80 (oxidized Incoloy 800 ). We determine $A=9.75$ for the first application and $A=2.63$ for the second. Figure 15 shows the two degradation profiles used in the model.

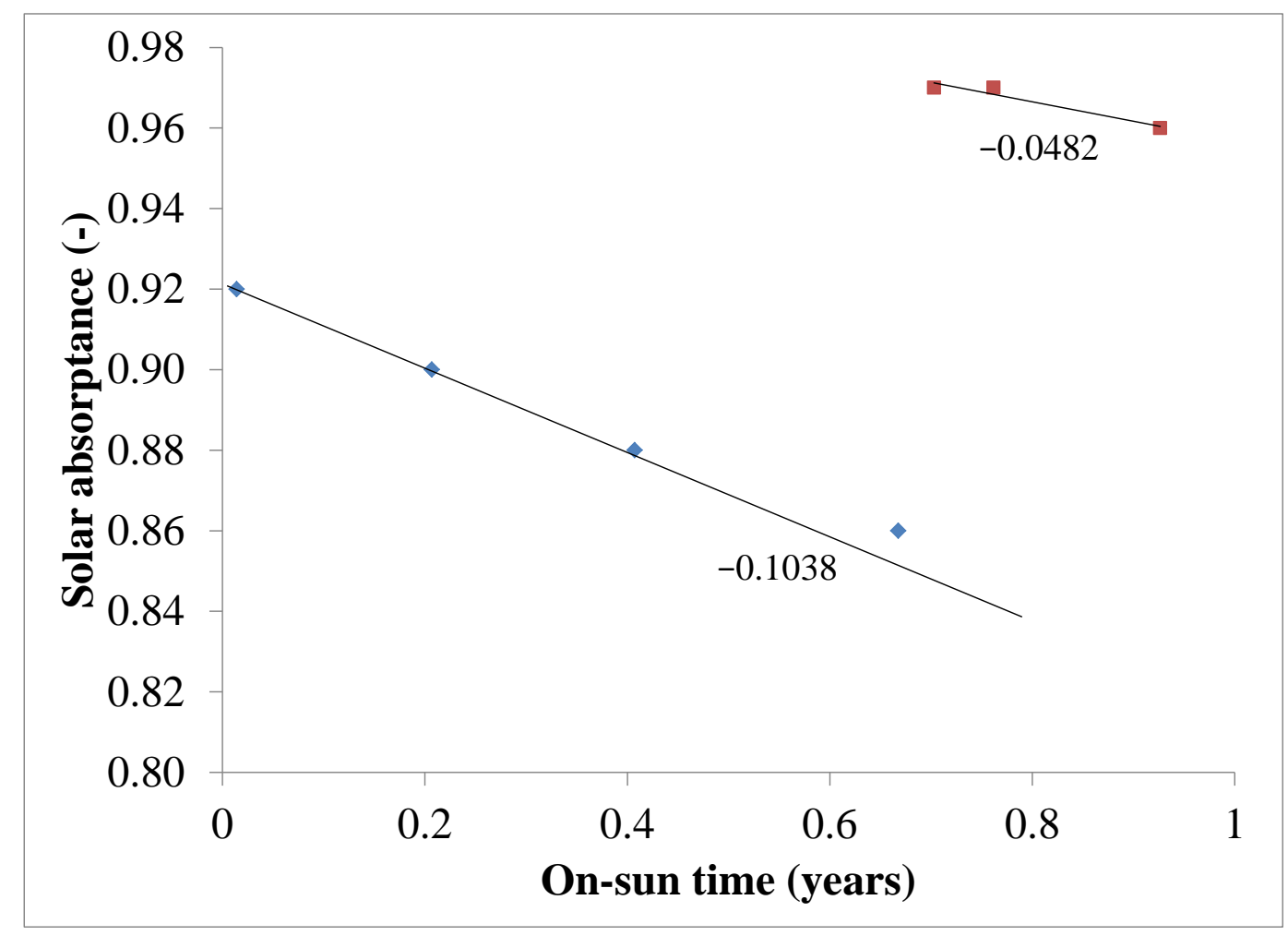

Figure 14. Solar absorptance of Solar One receiver at ambient temperature, as a function of the "on-sun" time. Due to the small amount of measurement points, the initial degradation slopes are calculated from linear regressions of both curves on the two and three first points, respectively. 


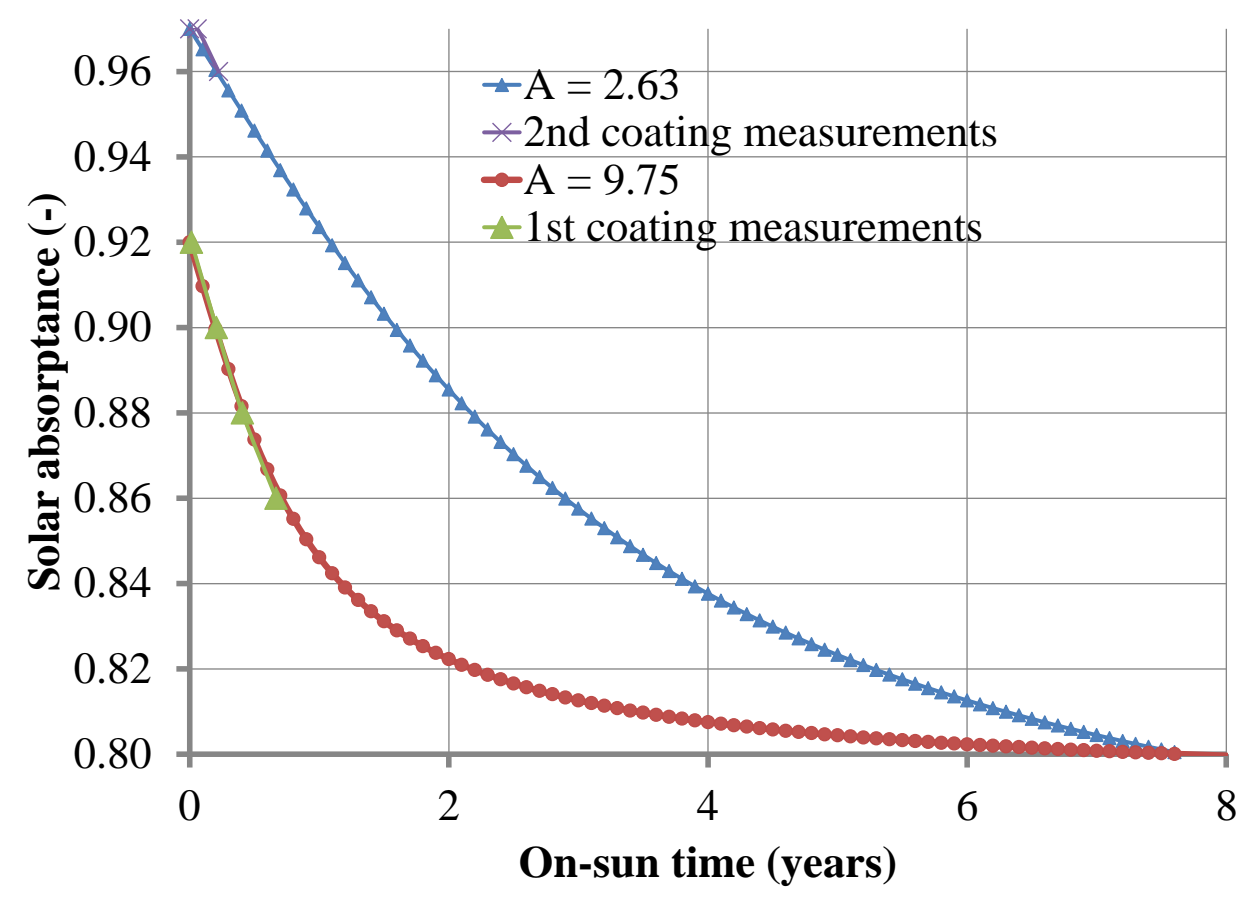

Figure 15. Two degradation profiles of Pyromark 2500 estimated from plotted Solar One receiver aging data. $x_{1}=0, D T=15$ days, $S L=30$ years. First coating: $A=9.75 \alpha_{0}=0.92, \alpha_{S L}=0.80$, second coating: $A=2.63 \alpha_{0}=0.97, \alpha_{\mathrm{SL}}=0.80$.

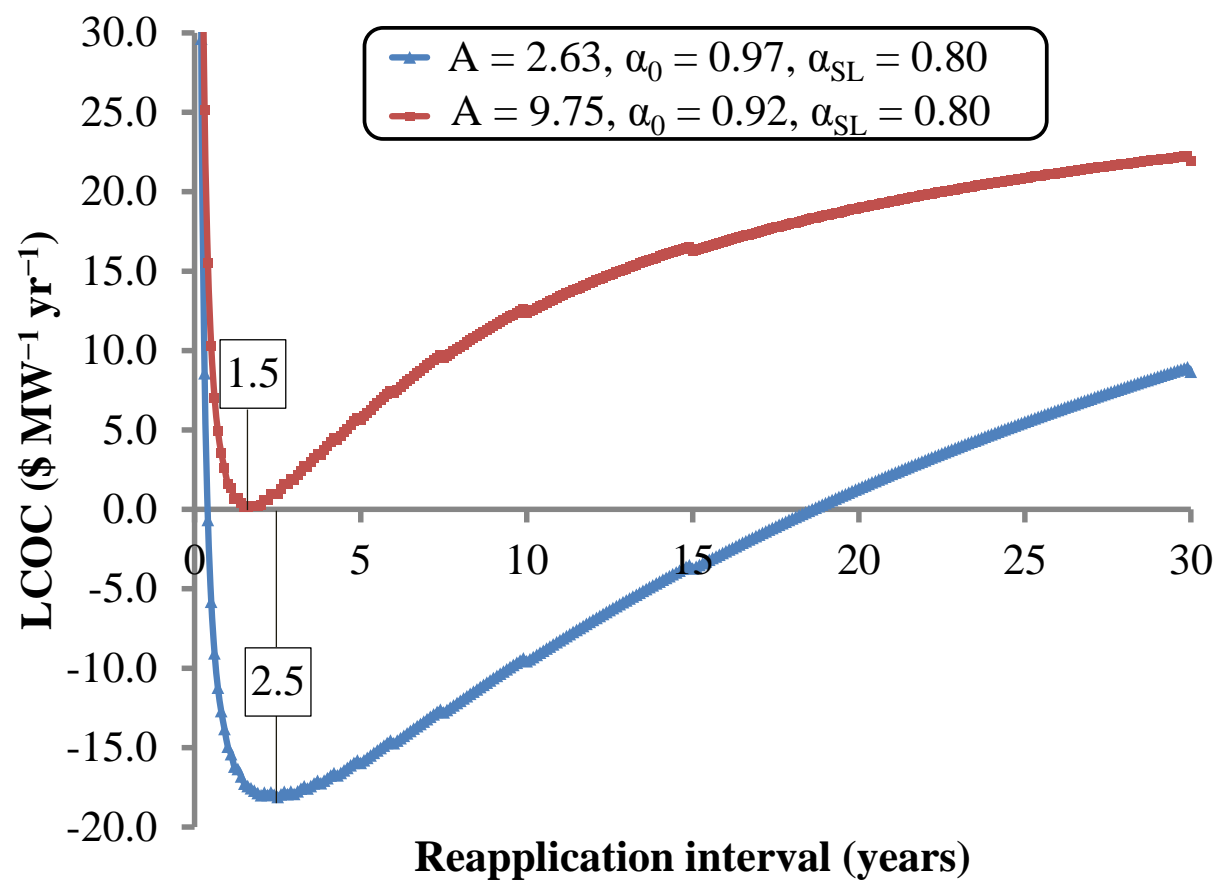


Figure 16. Absolute LCOC of Pyromark 2500 estimated from Solar One receiver aging data, for initial degradation rates of $0.1038\left(x_{1}=0, A=9.75 \alpha_{0}=0.97, \alpha_{S L}=0.80\right)$ and $0.0484\left(x_{1}=0, A=2.63 \alpha_{0}=0.97\right.$, $\left.\alpha_{S L}=0.80\right)$, respectively. $D T=15$ days, $S L=30$ years, $L C O E_{r e f}=\$ 232.5 \mathrm{MW}^{-1} \mathrm{~h}^{-1}$

Figure 16 shows the absolute LCOC of the two coatings with both degradation constants. We observe that for the higher $(A=9.75)$, the absolute LCOC is always positive which means that the coating increases the LCOE independent of the reapplication interval. A minimum is observed for a reapplication interval of 1.5 year but the LCOE is still $\$ 0.1 \mathrm{MW}^{-1} \mathrm{~h}^{-1}$ higher than the LCOE of the fictive uncoated receiver. The absolute LCOC of the second coating is negative when the reapplication interval is between 0.4 and 18.5 years. The absolute LCOC is minimized at a value of $-\$ 18.1 \mathrm{MW}^{-1} \mathrm{~h}^{-1}$ for a reapplication interval of 2.5 years. It would only be worthwhile to use the second coating.

Assuming the same tower with an ideal coating $\left(\alpha_{0}=1, \alpha_{\mathrm{SL}}=1, \varepsilon=0\right)$ available at no cost with an infinite durability (i.e. no degradation), the absolute LCOC would be $-\$ 55.2 \mathrm{MW}_{\mathrm{e}}^{-1} \mathrm{hr}^{-1}$. The corresponding LCOC efficiency values are $-0.2 \%$ for the first application and $32.8 \%$ for the second. This asserts the importance of using a coating that can sustain high performances and degrades the slowest possible.

The absolute LCOC of Pyromark is now estimated for a hypothetic future $100 \mathrm{MW}$ power tower with an annualized cost of $\$ 22,613,700 \mathrm{yr}^{-1}$ (see section 4.5) and $D T=5$ days (see Figure 17). The degradation profile of the second coating is used. In this futurist scenario, the absolute LCOC is negative between 0.3 and 18.2 years. It is minimized at $-\$ 5.6 \mathrm{MW}^{-1} \mathrm{~h}^{-1}$ for a reapplication interval of 2.0 years. The corresponding "LCOC efficiency" is $35.4 \%$.

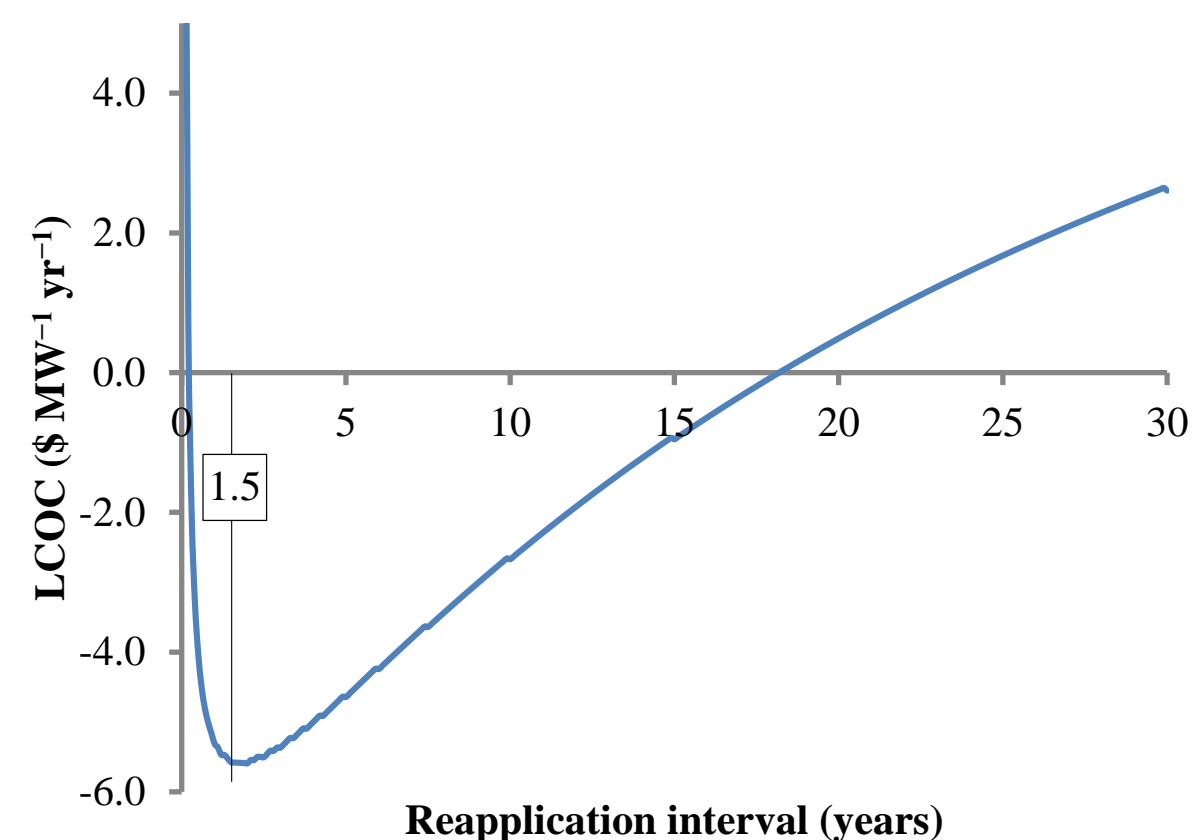

Figure 17. Absolute LCOC of Pyromark 2500 for a hypothetic future power tower. $x_{1}=0, A=2.73$ $\alpha_{0}=0.97, \alpha_{\mathrm{SL}}=0.80, D T=5$ days, $S L=30$ years, $L C O E_{\text {ref }}=\$ 66.4 \mathrm{MW}^{-1} \mathrm{~h}^{-1}$. The degradation constant is adjusted to maintain the initial degradation slope of -0.0484 . 


\section{Conclusion}

Power tower components are often qualified and ranked according to their maximum efficiency or performance. However, the durability is also an essential factor that must be taken into account to maximize the power output and minimize maintenance costs. In the CSP industry, efforts are underway to develop more efficient and durable coatings that will be used in next generation receivers. In order to quantify the cost-efficiency of coatings the absolute Levelized Cost of Coating (LCOC) model was developed. It uses the Levelized Cost of Energy (LCOE) metric to estimate the contribution of the coating to the LCOE. The model can simulate and evaluate the cost and energy gains of using specific coatings for various power tower designs.. Depending on the material, the coating technique, the aging and the energy generated, it is possible to reduce the LCOE by selecting the most cost effective coating. The absolute LCOC model can also be used as an optimization tool to minimize the operation and maintenance costs of a plant. In particular, it is possible to determine an optimal coating reapplication interval that minimizes the LCOE for a given degradation profile. The application of a receiver coating is generally profitable and enables a lower LCOE, except for very high degradation constants and very small or very large reapplication intervals $(R I<0.5 \mathrm{yr}$ or $R I>25 \mathrm{yr})$. In most cases, the absolute LCOC is minimized for a reapplication interval of 1 to 5 years. Typically, a reduction of up to $12 \%$ of the plant LCOE is possible thanks to the coating. The downtime for reapplication has small influence on the LCOE (about 1\%-2\% of the LCOE) but decreases the optimal reapplication interval by several years. The initial and reapplication costs of the coating have a reduced influence on the absolute LCOC compared to the degradation profile characteristics of the coating. Using a selective coating $\left(\alpha_{\mathrm{S}} \geq 0.95, \varepsilon_{\mathrm{T}} \leq 0.6\right)$ guaranties that the LCOE will be lowered, even at high degradation constants. Increasing the temperature of the receiver would significantly decrease the absolute LCOC of the selective coating, but would increase the absolute LCOC of the non-selective coating. Under the conditions investigated, a temperature higher than $600{ }^{\circ} \mathrm{C}$ would increase the LCOE of the plant in both cases. Enhanced influence of the thermal emittance at high temperature could make a non-selective coating uneffective compared to an uncoated receiver in the range $700{ }^{\circ} \mathrm{C}-800{ }^{\circ} \mathrm{C}$. Assuming a future power tower that meets the SunShot goals

$\left(\mathrm{LCOE} \leq \$ 60 \mathrm{MW}^{-1} \mathrm{~h}^{-1}\right.$ ), the receiver coating could be responsible for a decrease of $\$ 7.8 \mathrm{MW}^{-1} \mathrm{~h}^{-1}$ in the LCOE. Calculation of the absolute LCOC of Pyromark 2500 shows the importance of the coating degradation. In some cases with poor performance and high degradation constant - as observed after the first application of Pyromark on Solar One receiver-adding a coating would have a negative effect and increase the LCOE of the plant compared to an uncoated receiver. The calculation of the "LCOC efficiency" shows a value of about 30\% for Pyromark but predicts possible values of up to $50 \%$ for a selective coating. The absolute LCOC metric can potentially be adapted and used in other components of power plants to select the most cost-effective material, as well as the best operation and maintenance strategy. Characterization of materials aging and monitoring of their properties during the plant's service lifetime is crucial to refine the degradation profiles. New coatings and associated large-scale in-situ application techniques must be investigated to reduce the cost of reapplications and minimize downtime. Further developments such as partial recoating/replacement of receiver panels at prescribed intervals, or chemical/mechanical restoration of the absorber surface could help further absolute LCOC reductions. 


\section{Acknowledgments}

Sandia National Laboratories is a multi-program laboratory managed and operated by Sandia Corporation, a wholly owned subsidiary of Lockheed Martin Corporation, for the U.S. Department of Energy's National Nuclear Security Administration under contract DE-AC04-94AL85000. The United States Government and the publisher, by accepting the article for publication, acknowledges that the United States Government retains a non-exclusive, paid-up, irrevocable, world-wide license to publish or reproduce the published form of this manuscript, or allow others to do so, for United States Government purposes.

\section{References}

[1] Selvakumar N, Barshilia HC. Review of physical vapor deposited (PVD) spectrally selective coatings for mid- and high-temperature solar thermal applications. Sol Energy Mater Sol Cells 2012;98:1-23. doi:10.1016/j.solmat.2011.10.028.

[2] Raccurt O, Delord C, Bouquet C, Couturier R. Correlation between Solar Mirror Degradation and Colorimetric Measurement of Protective Back Layer. Proc SolarPACES 2013 Int Conf 2014;49:1700-7. doi:10.1016/j.egypro.2014.03.179.

[3] Fernández-García A, Cantos-Soto ME, Röger M, Wieckert C, Hutter C, Martínez-Arcos L. Durability of solar reflector materials for secondary concentrators used in CSP systems. Sol Energy Mater Sol Cells 2014;130:51-63. doi:10.1016/j.solmat.2014.06.043.

[4] Kennedy CE, Smilgys RV, Kirkpatrick DA, Ross JS. Optical performance and durability of solar reflectors protected by an alumina coating. Thin Solid Films 1997;304:303-9. doi:10.1016/S00406090(97)00198-3.

[5] Alami AH, Allagui A, Alawadhi H. Synthesis and optical properties of electrodeposited crystalline $\mathrm{Cu} 2 \mathrm{O}$ in the Vis-NIR range for solar selective absorbers. Renew Energy n.d. doi:10.1016/j.renene.2014.08.040.

[6] Farooq M, Raja IA. Optimisation of metal sputtered and electroplated substrates for solar selective coatings. Renew Energy 2008;33:1275-85. doi:10.1016/j.renene.2007.06.025.

[7] Joly M, Antonetti Y, Python M, Gonzalez M, Gascou T, Scartezzini J-L, et al. Novel black selective coating for tubular solar absorbers based on a sol-gel method. Sol Energy 2013;94:233-9. doi:10.1016/j.solener.2013.05.009.

[8] Moon J, Kim TK, VanSaders B, Choi C, Liu Z, Jin S, et al. Black oxide nanoparticles as durable solar absorbing material for high-temperature concentrating solar power system. Sol Energy Mater Sol Cells 2015;134:417-24. doi:10.1016/j.solmat.2014.12.004.

[9] Nuru ZY, Arendse CJ, Mongwaketsi N, Gohshal SK, Nkosi M, Maaza M. Effects of substrate temperatures on the thermal stability of $\mathrm{AlxOy} / \mathrm{Pt} / \mathrm{AlxOy}$ multilayered selective solar absorber coatings. Renew Energy 2015;75:590-7. doi:10.1016/j.renene.2014.10.050.

[10] Soum-Glaude A, Bousquet I, Thomas L, Flamant G. Optical modeling of multilayered coatings based on $\mathrm{SiC}(\mathrm{N}) \mathrm{H}$ materials for their potential use as high-temperature solar selective absorbers. Dye Sensitized Sol Cells Org Hybrid Sol Cells New Concepts Dye Sensitized Sol Cells Org Hybrid Sol Cells New Concepts 2013;117:315-23. doi:10.1016/j.solmat.2013.06.030.

[11] Setién-Fernández I, Echániz T, González-Fernández L, Pérez-Sáez RB, Céspedes E, SánchezGarcía JA, et al. First spectral emissivity study of a solar selective coating in the $150-600{ }^{\circ} \mathrm{C}$ temperature range. Dye Sensitized Sol Cells Org Hybrid Sol Cells New Concepts Dye Sensitized Sol Cells Org Hybrid Sol Cells New Concepts 2013;117:390-5. doi:10.1016/j.solmat.2013.07.002. 
[12] Nuru ZY, Msimanga M, Muller TFG, Arendse CJ, Mtshali C, Maaza M. Microstructural, optical properties and thermal stability of $\mathrm{MgO} / \mathrm{Zr} / \mathrm{MgO}$ multilayered selective solar absorber coatings. Sol Energy 2015;111:357-63. doi:10.1016/j.solener.2014.11.009.

[13] Céspedes E, Wirz M, Sánchez-García JA, Alvarez-Fraga L, Escobar-Galindo R, Prieto C. Novel Mo-Si3N4 based selective coating for high temperature concentrating solar power applications. Sol Energy Mater Sol Cells 2014;122:217-25. doi:10.1016/j.solmat.2013.12.005.

[14] Kennedy CE. Review of mid- to high-temperature solar selective absorber materials. National Renewable Energy Laboratory; 2002.

[15] Yousif KM, Smith BE, Jeynes C. Study of durability of (molybdenum-copper)-black coatings in relation to their use as solar selective absorbers. Clim Change Energy Environ 1994;5:324-9. doi:10.1016/0960-1481(94)90390-5.

[16] NREL. Transparent Cost Database 2014.

[17] Edenhofer O, Hirth L, Knopf B, Pahle M, Schlömer S, Schmid E, et al. On the economics of renewable energy sources. Suppl Issue Fifth Atl Workshop Energy Environ Econ 2013;40, Supplement 1:S12-23. doi:10.1016/j.eneco.2013.09.015.

[18] Ho CK, Pacheco JE. Levelized Cost of Coating (LCOC) for selective absorber materials. Sol Energy 2014;108:315-21. doi:10.1016/j.solener.2014.05.017.

[19] Setien E, Fernández-Reche J, Álvarez-de-Lara M, Ariza MJ. Experimental system for long term aging of highly irradiated tube type receivers. Sol Energy 2014;105:303-13. doi:10.1016/j.solener.2014.04.004.

[20] Ho CK, Mahoney AR, Ambrosini A, Bencomo M, Hall A, Lambert TN. Characterization of Pyromark 2500 Paint for High-Temperature Solar Receivers. J Sol Energy Eng 2013;136:014502014502. doi:10.1115/1.4024031.

[21] Boubault A, Claudet B, Faugeroux O, Olalde G. Accelerated Aging of a Solar Absorber Material Subjected to Highly Concentrated Solar Flux. Proc SolarPACES 2013 Int Conf 2014;49:1673-81. doi:10.1016/j.egypro.2014.03.176.

[22] Boubault A, Claudet B, Faugeroux O, Olalde G, Serra J-J. A numerical thermal approach to study the accelerated aging of a solar absorber material. Sol Energy 2012;86:3153-67. doi:10.1016/j.solener.2012.08.007.

[23] U.S. Department of Energy SunShot Initiative. SunShot Vision Study. 2012.

[24] Baker AF. 10 MWe Solar Thermal Central Receiver Pilot Plant Receiver Performance Final Report. Sandia National Laboratories; 1988. 